Revue d'histoire de l'Amérique française

REVUE D.HISTOIRE DE L'AMÉRIQUE FRANÇAISE

\title{
Corps, territoire et paysage à travers les images et les textes viatiques en Nouvelle-France (1701-1756)
}

\section{Stéphanie Chaffray}

Volume 59, numéro 1-2, été-automne 2005

URI : https://id.erudit.org/iderudit/012718ar

DOI : https://doi.org/10.7202/012718ar

Aller au sommaire du numéro

Éditeur(s)

Institut d'histoire de l'Amérique française

ISSN

0035-2357 (imprimé)

1492-1383 (numérique)

Découvrir la revue

Citer cet article

Chaffray, S. (2005). Corps, territoire et paysage à travers les images et les textes viatiques en Nouvelle-France (1701-1756). Revue d'histoire de l'Amérique française, 59(1-2), 7-52. https://doi.org/10.7202/012718ar
Résumé de l'article

À la fin de la période de la Nouvelle-France, les auteurs de relations de voyage semblent peu s'intéresser au paysage américain comparativement aux peuples autochtones sur lesquels ils concentrent leur attention. Cependant, si l'on analyse les récits et les gravures qui les illustrent en s'interrogeant sur la place consacrée au corps amérindien et au paysage, il est possible de voir que l'un et l'autre sont manipulés pour servir l'idéologie coloniale. Les Français prennent possession du territoire de manière symbolique, redéfinissent la relation entre les Amérindiens et l'environnement afin d'affirmer leur présence. Cet article explore la représentation du corps et du paysage dans les récits de voyage par le biais des problématiques d'appropriation et de pouvoir. 


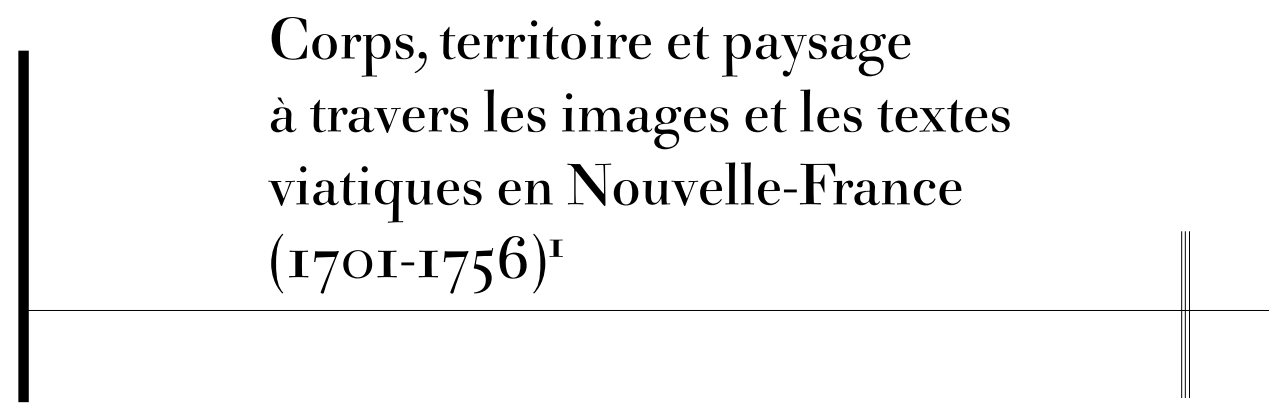

STÉPHANIE CHAFFRAY

Département d'histoire

Université Paris IV-Sorbonne/Université Laval

RÉSUMÉ - À la fin de la période de la Nouvelle-France, les auteurs de relations de voyage semblent peu s'intéresser au paysage américain comparativement aux peuples autochtones sur lesquels ils concentrent leur attention. Cependant, si l'on analyse les récits et les gravures qui les illustrent en s'interrogeant sur la place consacrée au corps amérindien et au paysage, il est possible de voir que l'un et l'autre sont manipulés pour servir l'idéologie coloniale. Les Français prennent possession du territoire de manière symbolique, redéfinissent la relation entre les Amérindiens et l'environnement afin d'affirmer leur présence. Cet article explore la représentation du corps et du paysage dans les récits de voyage par le biais des problématiques d'appropriation et de pouvoir.

ABSTRACT - Towards the end of the French regime in New France, authors of travel literature barely seemed interested in the American landscape, instead focusing their attention upon indigenous peoples. An analysis that concentrates on the space dedicated to the body and the landscape in the texts and engravings used by these authors reveals, however, that both were manipulated in order to reinforce the colonial ideology. The French symbolically appropriated the landscape, redefining the relationship between Amerindians and the environment in an effort to assert their presence. This paper explores the representation of the body and the landscape in travel literature from the point of view of appropriation and power.

1. Une première version de cet article a été présentée au séminaire "Le paysage: perceptions, représentations, théories. Appropriations du paysage et identités culturelles (XVIII ${ }^{\mathrm{e}}-\mathrm{XIX} \mathrm{e}^{\mathrm{e}}$ siècles)", qui s'est tenu de mars à juillet 2004 à l'Université de L ausanne, sous la direction des professeurs Claude Reichler (Université de Lausanne) et François Walter (Université de Genève), dans le cadre du 
la fin de la période de la Nouvelle-France, les Français tentent de
prendre possession du territoire ${ }^{2}$ nord-américain de façon matérielle en fondant des villes, en bâtissant des forts, en contrôlant les frontières politiques et les réseaux commerciaux. Ils le colonisent aussi de manière symbolique à travers le discours transmis par les récits de voyage. Les représentations littéraires et iconographiques véhiculées par ces textes traduisent la volonté de connaître l'espace et les groupes amérindiens dont le soutien est plus que jamais vital face aux prétentions hégémoniques de la Grande-Bretagne. Ces représentations, qui résultent de l'expérience physique des voyageurs, transforment l'environnement américain en paysage et redéfinissent la place qu'y occupent à la fois les Autochtones et les Européens.

Le paysage est une émotion, une manière personnelle de lire et de se représenter un environnement ${ }^{3}$. Il traduit la relation des voyageurs à l'espace ou à la nature ${ }^{4}$. Le paysage permet d'exprimer une identité. Les Français ont perçu le milieu naturel en fonction de leurs propres intérêts et de leur culture. Ils ont utilisé le paysage de la Nouvelle-France de façon politique ${ }^{5}$, afin d'affirmer leur présence et de s'approprier symboliquement le territoire ${ }^{6}$. Et cette présence s'est confrontée à celle des différentes

projet IRIS 4. Je tiens à les remercier tous deux, pour leur aide et leurs précieux conseils, ainsi que les participants au séminaire pour leurs suggestions. Une autre version a été présentée au Congrès annuel 2004 de l'Institut d'histoire de l'Amérique française. Une autre version, en anglais, a donné lieu à une conférence à la John Carter Brown Library (JCBL). Cette étude a considérablement été enrichie par les recherches menées dans cette institution en automne 2004. Je tiens, à cet égard, à remercier chaleureusement Norman Fiering pour son soutien et son aide ainsi que tout le personnel de la JCBL. Je remercie également la JCBL pour l'autorisation de publier une grande partie des images de cet article. Ma gratitude va également à Jean-Pierre Poussou et Laurier Turgeon. Cette recherche a été rendue possible par le soutien financier du projet IRIS IV (Lausanne), de la John Carter Brown Library et du CELAT (Université Laval). Je tiens à remercier, finalement, les évaluateurs anonymes de la RHAF pour leurs commentaires et suggestions très constructifs.

2. Le territoire est entendu ici comme l'«appropriation corporelle de l'espace» et la «réappropriation émotionnelle du temps " par un groupe social ou un individu; Jean-Claude Piveteau, Temps du territoire (Carouge, Genève, Zoé, 1995), 6.

3. Alain Corbin, L'homme dans le paysage (Paris, Textuel, 2001), 11.

4. Selon le géographe Augustin Bercque, le paysage est «l'expression sensible de la relation d'un sujet individuel ou collectif à l'espace ou à la nature "; Augustin Bercque, Le Sauvage et l'artifice. Les Japonais devant la nature (Paris, Gallimard, 1986), 154. Sur les autres définitions du paysage, voir Claude Reichler, La découverte des Alpes et la question du paysage (Genève, Georg éditeur, 2002), 12-19.

5. Selon François Walter, «il existe, des usages politiques du paysage»; François Walter, Les figures paysagères de la Nation. Territoire et paysage en Europe (16 $6^{\mathrm{e}}-20^{\mathrm{e}}$ siècles) (Paris, EHESS, 2004), 12.

6. Le paysage est une production culturelle: chaque société entretient un rapport différent avec son environnement, tisse des liens avec lui et en élabore des représentations. François Walter parle d'une «médiation à la terre par le paysage», F. Walter, Les figures paysagères..., op. cit., 12. Le 
nations amérindiennes. Étant donné ce contexte, on peut se demander comment les Français ont représenté les autochtones dans l'environnement américain. En d'autres termes: quelle place ont-ils accordée au corps amérindien ${ }^{7}$ dans le paysage?

Un tel sujet surprendra peut-être le lecteur étant donné que le paysage semble - au premier abord - n'avoir que modérément retenu l'attention des voyageurs. Ils donnent peu de détails concernant le milieu naturel comparativement aux populations autochtones sur lesquelles ils focalisent leur intérêt et leur curiosité. Le même constat pourrait être fait à propos des gravures, qui sont pauvres en indications sur la nature américaine et qui semblent souvent manquer de réalisme ${ }^{8}$. Ce désintérêt apparent des voyageurs et des graveurs est à replacer dans le contexte de la littérature et de la peinture de l'époque qui s'intéressent encore assez peu au paysage. Il faut attendre le $\mathrm{XIX}^{\mathrm{e}}$ siècle pour que ce dernier devienne un sujet d'étude à part entière 9 .

Dans un tel contexte, pourquoi s'attarder sur une question que les voyageurs semblent avoir négligée ? La première raison tient à l'originalité de l'espace colonial français au cours de la première moitié du xviII ${ }^{\mathrm{e}}$ siècle. La Nouvelle-France se trouve alors à l'apogée de son expansion territoriale et couvre un espace immense allant de l'Acadie à l'embouchure du Mississipi. En raison de son étendue, cet espace est extrêmement varié tant au niveau des ressources naturelles, du climat que des sociétés autochtones. On peut se demander comment cette variété se traduit dans les représentations du paysage.

massif alpin, par exemple, a été un élément majeur dans la formation de l'identité suisse de la fin du xviII siècle jusqu'à la Seconde Guerre mondiale; voir Elias Canetti, Masse und Macht (Hamburg, Claassen Verlag, 1971), 191-203 ; voir également, Oliver Zimmer, «In Search of Natural Identity: Alpine Landscape and the Reconstruction of the Swiss Nation ", Comparative Studies in Society and History, 40,4 (octobre 1998): 637-665.

7. Le concept de corps est entendu ici de manière large : il englobe les dimensions anatomique, comportementale et technique du corps aussi bien que les représentations. Le corps est une construction sociale complexe. Il est le siège à la fois de l'individualité et de l'attachement à une société; voir à ce sujet Christine Detrez, La construction sociale du corps (Paris, Seuil, 2002). Le corps peut être investi de différentes formes de pouvoir; voir Mary Douglas, De la souillure: essai sur les notions de pollution et de tabou (Paris, la Découverte et Syros, 2001); voir aussi Michel Foucault, Surveiller et punir (Paris, Gallimard, 1997). Dans le cadre de la rencontre entre Européens et Amérindiens à l'époque coloniale, il peut être un instrument politique et être soumis à des phénomènes d'acculturation et de transferts culturels.

8. Réal Ouellet relevait l'absence de paysages dans les gravures de Lahontan; Réal Ouellet, "Le discours des gravures dans les Voyages de Lahontan (1702-1703)", Études de Lettres, «Mots et images nomades", 1-2 (janvier-juin 1995): 36-37.

9. François Walter, Les Suisses et l'environnement, une histoire du rapport à la nature du XVIII ${ }^{\mathrm{e}}$ siècle à nos jours (Genève, éd. Zoé, 1990), 46-51. 
La seconde raison est l'originalité de la période. Pendant la première moitié du xviII ${ }^{\mathrm{e}}$ siècle, le milieu américain est à la fois nouveau (pour les voyageurs qui débarquent) et connu (les Français voyagent au Canada et le décrivent depuis deux siècles). L'ont-ils domestiqué ou demeure-t-il sauvage? Cette période est également marquée par l'accroissement des tensions avec la Grande-Bretagne et par la volonté des Français de contrôler et d'étendre l'espace colonial. Comment cette politique se traduit-elle dans la représentation du paysage? La plupart des voyages sont en effet entrepris pour des motifs coloniaux et si certains - comme le baron Lahontan - sont plus critiques envers le colonialisme, tous les voyageurs défendent l'idéologie coloniale.

Un autre motif pour étudier cette période tardive de la Nouvelle-France est que, depuis le $\mathrm{xvI}^{\mathrm{e}}$ siècle, les observateurs européens remarquent la relation étroite que les Amérindiens entretiennent avec le milieu naturel. Cette perception a-t-elle évolué? Cette proximité entre l'homme et la nature se reflète-t-elle dans la représentation du paysage? Quelle place est donnée au corps dans le paysage? Est-il lui aussi instrumentalisé dans le discours des voyageurs ${ }^{10}$ ?

C'est cette relation triangulaire entre corps, paysage et pouvoir que je voudrais mettre en évidence en analysant le rapport sémantique entre corps et paysage. Cet article analyse comment - à une époque où le paysage intéresse peu a priori la littérature et l'art pictural - les voyageurs ont perçu le paysage américain et de quelle manière les graveurs ont mis en image leurs descriptions. Il s'agit de réfléchir à la représentation du corps et du paysage à partir des problématiques d'appropriation et de pouvoir dans les descriptions textuelles et dans les gravures illustrant les récits de voyage. Cela permettra de comprendre comment le discours colonial manipule le corps et le paysage pour se les approprier.

L'historiographie de la Nouvelle-France révèle l'absence d'études sur un tel sujet. Peu de travaux historiques ont été réalisés sur les gravures illustrant les récits de voyage. Si quelques-unes de ces images ont fait l'objet d'analyses ponctuelles, la plupart ne sont utilisées qu'à titre d'illustration et n'ont jamais donné lieu à une étude historique approfondie. De plus, l'approche comparative entre texte et image est fondamentale puisque les

10. L'historienne Joyce Chaplin a montré comment les colons britanniques ont cherché à prouver la supériorité de leur corps en opposition au corps des autochtones fragile et inadapté au milieu et au climat, ce qui leur a permis de renforcer l'idée qu'ils étaient un peuple élu; Joyce Chaplin, Subject Matter. Technology, the Body, and Science on the Anglo-American frontier, 1500-1676 (Cambridge, Harvard University Press, 2001). 
gravures étaient généralement réalisées en Europe par des artistes travaillant à partir des descriptions fournies par les voyageurs; de là, il convient de s'interroger sur les continuités et les ruptures entre texte et image. Ensuite, les études portant sur les Amérindiens dans les récits de voyage ont souvent abordé leur représentation comme des stéréotypes, des miroirs de la culture européenne ou de la politique coloniale et ont eu tendance à isoler les sujets du cadre paysager ${ }^{11}$. Étudier le corps amérindien dans le paysage permet de saisir la complexité de ces représentations et de comprendre le rôle actif qu'elles ont joué dans l'histoire de la Nouvelle-France comme éléments des discours colonial et anticolonial. D’un point de vue bibliographique, une étude manque également pour rendre compte de la représentation du paysage de la Nouvelle-France. À l'exception de deux ouvrages sur l'hiver canadien ${ }^{12}$, le seul à avoir abordé cette question est Paolo Carile qui s'est intéressé au paysage dans les récits des $\mathrm{XVI}^{\mathrm{e}}$ et $\mathrm{xvII}^{\mathrm{e}}$ siècles ${ }^{13}$. Il se concentre exclusivement sur le texte dont il propose une analyse littéraire très intéressante, mais laisse de côté les gravures qui l'accompagnent. L'historien canadien John Crowley a publié récemment un article très intéressant sur l'appropriation du paysage de la Nouvelle-France par les Britanniques après la Conquête ${ }^{14}$. Il ne s'intéresse cependant qu'aux représentations topographiques. Ce désintérêt pour le paysage n'est cependant pas le seul fait des historiens de la Nouvelle-France. Les historiens en

11. Plusieurs historiens se sont intéressés aux origines de l'image des Amérindiens dans la culture européenne; voir entre autres Olive P. Dickason, Le Mythe du Sauvage (Sillery, Septentrion, 1993); voir Cornelius Jeanen, «Pelleteries et peaux-rouges : perceptions françaises de la NouvelleFrance et ses peuples indigènes aux Xvi ${ }^{\mathrm{e}}, \mathrm{XvII}^{\mathrm{e}}$ et XVIII ${ }^{\mathrm{e}}$ siècles ", Recherches amérindiennes au Québec, XIII,2 (1983): 107-114; voir François-Marc Gagnon, Hommes effarables et bestes sauvaiges (Montréal, Boréal, 1986), 220; voir également Robert F. Berkhofer, The White Man's Indian. Images of the American Indian from Colombus to the Present (New York, Alfred A. Knopf, 1978). Des études historiques plus récentes ont insisté sur le contenu politique des représentations des autochtones; voir notamment Annie Jacob, «L'Indien des Anglais, l’Indien des Français : images comparées », dans Gilles Thérien, dir., Les figures de l'Indien (Montréal, Université du Québec à Montréal, 1988), 193205 ; voir également Jean Levesque, «Représentations de l'autre et propagande coloniale dans les récits de John Smith en Virginie et de Samuel de Champlain en Nouvelle-France», Canadian Folklore, 17,1 (1995): 103-123; ou encore, Gordon Sayre, Les Sauvages Américains : Representations of Native Americans in French and English Colonial Literature (Chapel Hill, University of North Carolina Press, 1997).

12. Sophie-Laurence Lamontagne, L'hiver dans la culture québécoise (XVII ${ }^{\mathrm{e}}$-XIX ${ }^{\mathrm{e}}$ siècles) (Québec, Institut québécois de recherche sur la culture, 1983); Paulette Collet, L'hiver dans le roman canadienfrançais (Québec, Les Presses de l’Université Laval, 1965).

13. Paolo Carile, Le regard entravé : littérature et anthropologie dans les premiers textes de la NouvelleFrance (Sillery, Septentrion, 2000), 23.

14. John Crowley, "'Taken on the Spot": The Visual Appropriation of New France for the Global British Landscape», Canadian Historical Review, 86,1 (mars 2005): 1-28. 
général se sont peu penchés sur cette question ${ }^{15}$, contrairement aux géographes, historiens de l'art et littéraires, chez qui ce sujet a généré de nombreuses réflexions. Cette réticence des historiens viendrait du fait que le paysage relève de l'émotion, du ressenti et de l'impalpable. Et pourtant, il est un élément essentiel du fonctionnement des sociétés humaines : il est la marque de leur attachement et de leur adaptation à l'environnement et participe à la construction des identités ${ }^{16}$.

Cet article voudrait amorcer une réflexion sur certaines de ces questions délaissées par les historiens de la Nouvelle-France et explorer comment les auteurs de relations et les graveurs ont montré - ou occulté - le paysage et le corps à la fin du Régime français. Dans un premier temps, j’analyserai comment les voyageurs représentent l'espace naturel, puis de quelle manière ils cherchent à le connaître, à le catégoriser et à se l'approprier. Ensuite, je me demanderai quelle place le corps amérindien occupe dans le paysage et enfin quelle relation le colonisateur établit avec l'espace colonisé.

\section{I - LA VISION UTILITARISTE DE LA NATURE}

Le paysage est une lecture personnelle d'un espace et c'est aussi une construction culturelle ${ }^{17}$. Son acception, indissociable du rapport à la nature, varie d'une société à une autre et évolue au cours du temps. En Europe, le concept de paysage naît aux $\mathrm{xv}^{\mathrm{e}}$ et $\mathrm{xvI}^{\mathrm{e}}$ siècles, mais n'apparaît réellement dans les textes qu'au $\mathrm{xviII}^{\mathrm{e}}$ siècle $^{18}$. Depuis Descartes et jusqu'au siècle des Lumières, la nature est perçue de manière techno-scientifique. Identifiée à la matière, elle doit être domestiquée par l'homme et intégrée dans l'horizon de la technique ${ }^{19}$. Le «beau paysage» est le paysage bordé, cultivé et ordonné ${ }^{20}$. Si le goût pour une esthétique naturelle naît au $\mathrm{XVIII}^{\mathrm{e}}$ siècle, il ne s'épanouit pleinement qu'au siècle suivant avec l'émergence de la perception romantique de la nature. Au xviII ${ }^{\mathrm{e}}$ siècle, le

15. À la fin des années 1960, Marc Bloch déplorait déjà la désertion des historiens de ce champ de recherche: «Dans la vue que j'ai de ma fenêtre chaque savant prend son bien sans trop s'occuper de l'ensemble"; Marc Bloch, Apologie pour l'histoire ou le métier d'historien (Paris, A. Colin, 1967), 76; cité par F. Walter, Les figures paysagères..., op. cit., 7.

16. F. Walter, Les figures paysagères..., ibid.; Alain Corbin, L'homme dans le paysage..., op. cit.

17. Alain Corbin, ibid., 11-12.

18. Sur l'histoire du mot paysage, voir Catherine Franceschi, «Du mot paysage et de ses équivalents dans cinq langues européennes», dans Michel Collot, dir., Les enjeux du paysage (Bruxelles, Ousia, 1997), 75-111.

19. Jean-Marc Besse, Isabelle Roussel, Environnement : représentations et concept de la nature (Paris, L'Harmattan, 1997), 41.

20. Alain Corbin, L'homme dans le paysage..., op. cit., 86. 
paysage s'inscrit avant tout dans le projet technique d'utilisation de la nature ${ }^{21}$.

Comment une telle conception s'intègre-t-elle dans le contexte colonial? La conception techno-scientifique de la nature trouve parfaitement sa place dans l'idéologie coloniale dont le fondement est l'enrichissement de la métropole par le commerce. La nature du pays colonisé est vue avant tout comme un réservoir potentiel de richesses. C'est pourquoi, dans les témoignages des voyageurs, la diversité des paysages reflète surtout la situation géopolitique des différents espaces coloniaux. Si les «quelques arpents de neige du Canada » divisent les commentateurs quant à l'intérêt de la Nouvelle-France, ou si la région de la Baie d'Hudson est pour Nicolas Jérémie, au début du $\mathrm{xvIII}^{\mathrm{e}}$ siècle, "un pays tout à fait inculte et le plus ingrat de tous les pays du monde ${ }^{22}$ », la Louisiane et la région des Grands Lacs suscitent - quant à elles - des commentaires beaucoup plus positifs. Ce sont ces deux régions qui font l'objet des représentations les plus nombreuses et les plus idéalistes. À la fin du xvII ${ }^{\mathrm{e}}$ siècle, le baron de Lahontan écrit que la région du lac Érié est

d'un aspect si charmant qu'on voit le long de ses bords des Chênes, des Ormeaux, des Châtaigniers, des Noyers, des Pommiers, des Pruniers, et des Treilles, qui portent leurs belles grappes jusqu'au sommet des arbres sur un terrain uni comme la main, ce qui doit suffire pour s'en former l'idée d'un monde le plus agréable. Je ne saurais d'ailleurs vous exprimer la quantité de bêtes fauves et de poulets d'Inde qu'on voit dans ces bois et dans les vastes prairies, qu'on découvre du côté du $\operatorname{sud}^{23}$.

Le père Charlevoix qui visite la région dans les années 1720 se dit «enchanté de la beauté et de la variété d'un paysage, terminé par les plus belles forêts du monde ${ }^{24}$ ». La vision édénique du paysage est un lieu commun de la littérature de voyage, elle s'inscrit dans la tradition poétique du Locus Amoenus ${ }^{25}$. L'Amérique serait une sorte de paradis perdu. La métaphore du jardin d'Eden est aussi un élément de la rhétorique impériale. Le paysage sert de

21. F. Walter, Les Suisses et l'environnement, op. cit., 35-51; voir aussi F. Walter, Les figures paysagères..., op. cit. , 14.

22. Nicolas Jérémie, «Relation de la Baie d'Hudson par Nicolas Jérémie» dans J.-F. Bernard, Recueil de voyages au nord, contenant divers mémoires très utiles au commerce et à la navigation (Amsterdam, 1715-38), V: 307-309.

23. Lahontan, Euvres complètes (Montréal, Presses de l'Université de Montréal, 1990), 546.

24. Pierre François-Xavier Charlevoix, Histoire et description générale de la Nouvelle-France: avec le journal historique d'un voyage fait par ordre du roi dans l'Amérique Septentrionale, par le R.P. Charlevoix, de la Compagnie de Jésus (Paris, Chez Rolin fils, 1744), V: 374.

25. Voir Stephen Greenblatt, Ces merveilleuses possessions (Paris, Belles lettres, 1996). 
projection aux désirs d'empires des colonisateurs. À la fin du xvII ${ }^{\mathrm{e}}$ siècle, par exemple, Lamothe Cadillac, qui cherche à convaincre la Couronne d'établir une colonie à Détroit et de l'en nommer gouverneur, offre plusieurs descriptions très lyriques de la région: «Peut-on croire qu’une terre sur laquelle nature a distribué toutes choses avec tant d'ordre sache refuser à la main du curieux laboureur qui rompra ses fécondes entrailles, le retour qu'il s'en sera proposé $^{26}$ ?» Cette vision paradisiaque favorise les objectifs personnels de Cadillac. Les descriptions enchanteresses sont également "utilitaristes» puisqu'elles servent à appuyer le projet colonial.

La Louisiane fait l'objet, elle aussi, de descriptions édéniques. Au début du siècle, le chevalier de Bonrepos vante les richesses de la Louisiane: «L'abondance y règne tant en grains qu'en fruits et en bétail, mines de plomb de cuivre et de fer. Il pourrait rendre le royaume de France aussi riche que le Pérou ${ }^{27}$.» La nature généreuse constitue donc une invitation à la colonisation. Le même discours se retrouve en $1717 \mathrm{chez}$ un auteur anonyme, selon lequel le paysage environnant la rivière de la Mobile «est beau, uni, coupé de plusieurs autres petites rivières, et couvert de bois presque partout. La terre y produit presque tous les légumes, et les arbres fruitiers de France; elle n'attend que les soins du laboureur, pour produire tout ce qui peut être nécessaire à la vie ${ }^{28}$.» L'association entre beauté,

26. Lamothe Cadillac, Relation du Sieur de Lamothe-Cadillac, Capitaine en pieds ayant une compagnie de la marine en Canada ci-devant commandant de Missilimakinac et autres postes dans les pays éloignés où il a été pendant 3 années, dans Pierre Margry, Mémoires et documents pour servir à l'histoire des pays d'Outre-Mer. Découvertes et établissements des Français dans l'Ouest et dans le sud de l'Amérique Septentrionale (Paris, Maisonneuve et Cie, 1879-1888), V: 192-194.

27. Chevalier de Bonrepos, Description du Mississipi; le nombre de villes et de colonies établies par les Français, les isles, rivières et territoires qui les bordent... Les mœurs et négoces des sauvages qui y habitent, la manière de se faire la guerre et la paix... (Paris, B. Gyrin, 1720), 43.

28. Anonyme, «Relation de la Louisiane ou Mississippi. Écrite à une dame, pas un officier de marine », dans J.-F. Bernard, dir., Relations de la Louisiane, et du fleuve Mississippi, où l'on voit l'état de ce grand païs \& les avantages qu'il peut produire (Amsterdam, Jean Frédéric Bernard, 1720), 10. L’ingénieur du roi Franquet émet le même type de commentaire «ces terres cultivées par gens entendus et dans des saisons propices peuvent produire tout ce que l'on peut s'imaginer ", Charles Franquet de Chaville, «Récit de voyage de la Louisiane fait pendant les années 1720-1724 par Franquet ingénieur ordinaire du Roi ", Journal de la Société des Américanistes de Paris (1902): 34 ; voir aussi le R. P. Lepetit, «Relation des Natchez contenue dans une lettre du Père Lepetit, missionnaire de la compagnie de Jésus. Au P. Davaugour de la même compagnie, procureur des missions de l'Amérique Septentrionale", dans J.-F. Bernard, Recueil de voyages au nord, contenant divers mémoires très utiles au commerce et à la navigation (Amsterdam, 1715-1738), IX: 2; voir aussi Emmanuel Crespel, Voiages du Révérend Père Crespel dans le Canada et naufrage en revenant en France, mis à jour par le Sieur Louis Crespel son frère (Franckfort-sur-le-Meyn, 1742), 32; Marie-Madeleine Hachard, Relation du voyage des dames Urselines de Rouen à la Nouvelle-Orléans en 1727 (Paris, Maisonneuve, 1872), 33 . 
abondance et virginité dans la description des paysages de la Louisiane perdure jusque dans les années 1750 , comme on peut le voir chez JeanBernard Bossu, pour qui les terres des Chicachas sont «les plus belles et les plus fertiles du continent ${ }^{29}$ ». Nous le constatons ici, le paysage est un outil politique au service de l'idéologie coloniale. Le discours colonial réutilise la conception utilitariste de la nature et s'en sert d'argument pour se justifier. L'idée d'une terre vierge offerte à la main du colonisateur
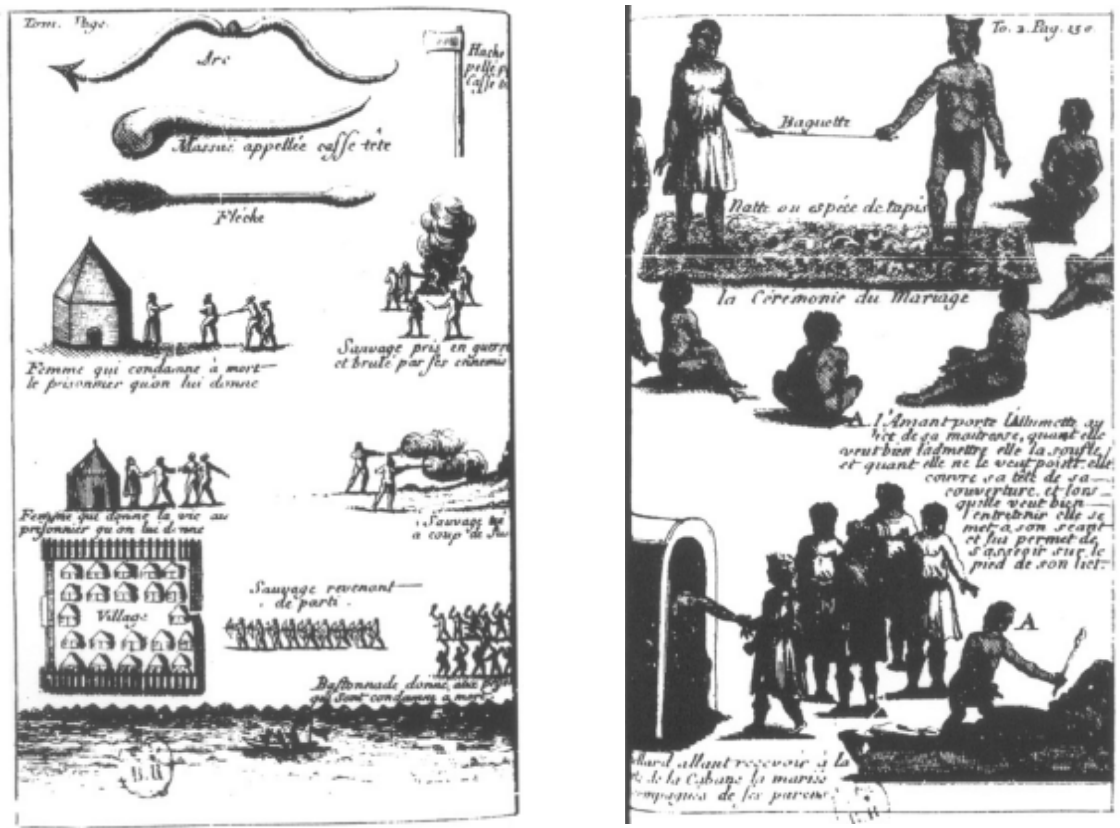

Images 1 et 2: Louis Armand de Lom d'Arce, Baron de Lahontan, Mémoires de l'Amérique Septentrionale ou les Suite des voyages de Mr le Baron de Lahontan. Qui contiennent la description d'une grande étendue de païs de ce continent, l'intérêt des Français et des Anglais, leurs commerces, leurs navigations, les mours et les coutumes des Sauvages, \& $\sigma$. avec un petit dictionnaire de la langue du païs, le tout enrichi de cartes \& de figures, et augmenté dans ce second tome de la manière dont les sauvages se régalent (La Haye, chez les Frères l'Honoré, 1703), image 1: II: 185 ; image 2: II: 133 ; tirées de Lahontan, Euvres complètes (Presses de l’Université de Montréal, 1990).

29. Jean-Bernard Bossu, Nouveaux voyages aux Indes Occidentales; contenant une relation des différents peuples qui habitent les environs du grand fleuve Saint-Louis, appelé vulgairement le Mississippi, leur religion; leur gouvernement; leurs mours; leurs guerres et leur commerce (Paris, Le Jay, 1768), II: 107; Bossu fait aussi une description élogieuse de la région des Akanças: «Le pays des Akansas est un des plus beaux du monde; les terres y si sont fertiles, qu'elles produisent presque sans culture, du froment d'Europe, toutes sortes de légumes et de bons fruits inconnus en France; le gibier de toute espèce y abonde, comme bœufs sauvages, cerfs, chevreuils, ours, tigres...»; ibid., I: 110 . 


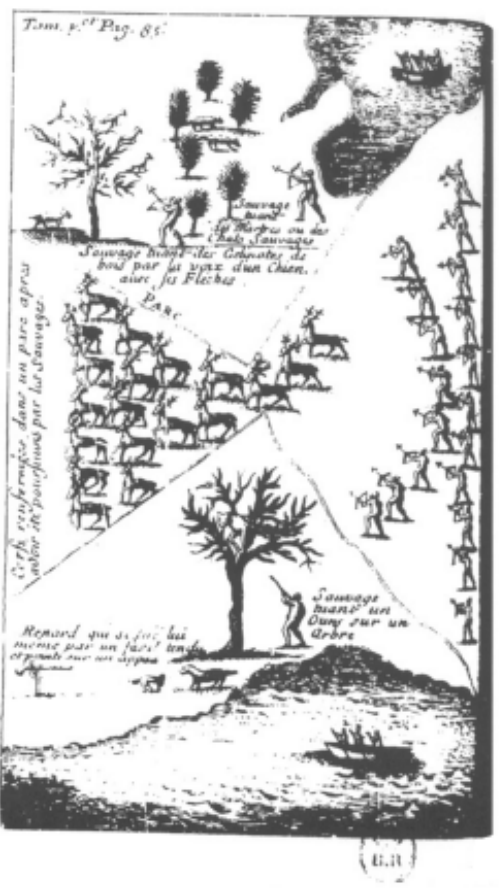

Image 3 : Louis Armand de Lom d'Arce, Baron de Lahontan, op. cit., V: 85 ; tirée de Lahontan, op. cit.

renvoie à l'idée développée par l'historienne Ludmilla Jordanova selon laquelle la nature, au XviII ${ }^{\mathrm{e}}$ siècle, est souvent identifiée à la féminité. La "nature-femme» aurait besoin de la "civilisation-homme» pour sortir de l'état de passivité à laquelle elle est réduite ${ }^{30}$. Ce schéma pourrait être appliqué à la littérature de voyage du $\mathrm{xvIII}^{\mathrm{e}}$ siècle, celle-ci étant le résultat d'expériences majoritairement masculines et orientées vers la conquête. Il est alors possible de l'analyser suivant ce paradigme: le voyageur, en décrivant le paysage, colonise la nature qui s'offre à lui.

La générosité de la nature décrite par les voyageurs ne se reflète pas dans l'iconographie. Si nous regardons les images de Lahontan en 1703 (images 1, 2 et 3), de Lafitau (images 4 et 5), de Bacqueville de la Potherie (image 7) quelque vingt années plus tard ou de Le Page Du Pratz (images 16 et 17 ) dont le récit paraît en $1758^{31}$, le paysage semble, au

30. Ludmilla Jordanova, Sexual Visions: Images of Gender in Science and Medicine Between the Eighteenth and Twentieth Centuries (Madison, University of Wisconsin Press, 1989); voir, particulièrement, les chapitres II et III.

31. Étant donné que les gravures étaient réalisées en Europe après le voyage, je prends en compte ici, non pas la date du voyage, mais la date de publication de l'ouvrage. 

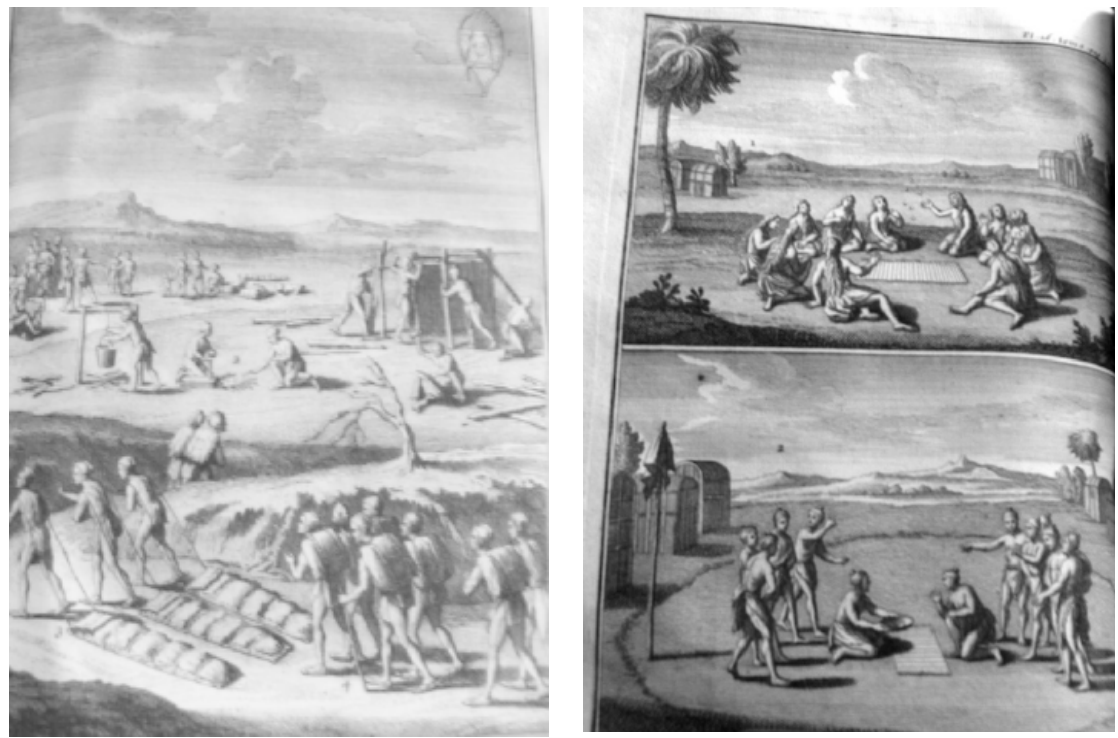

Images 4 et 5 : Joseph François Lafitau, Mœurs des sauvages ameriquains comparées aux mœurs des premiers temps (Paris, Chez Saugrain l'aîné, Charles-Estienne Hochereau, 1724), image $4: \mathrm{II}: 220$; image $5:$ II : 340.

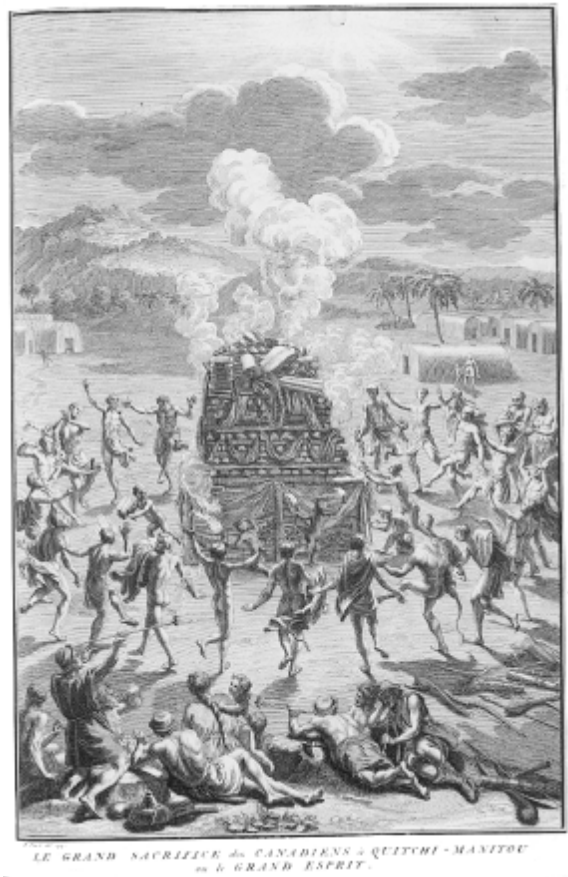

Image 6: Gravure de Bernard Picart, dans J.-F. Bernard, Cérémonies et coutumes religieuses des peuples idolatres, / représentés par des figures dessinées de la main de Bernard Picart; avec une explication historique et quelques dissertations curieuses (Amsterdam, chez Jean-François Bernard, 1723-1728), I, $1: 84$. The John Carter Brown Library at Brown University. 


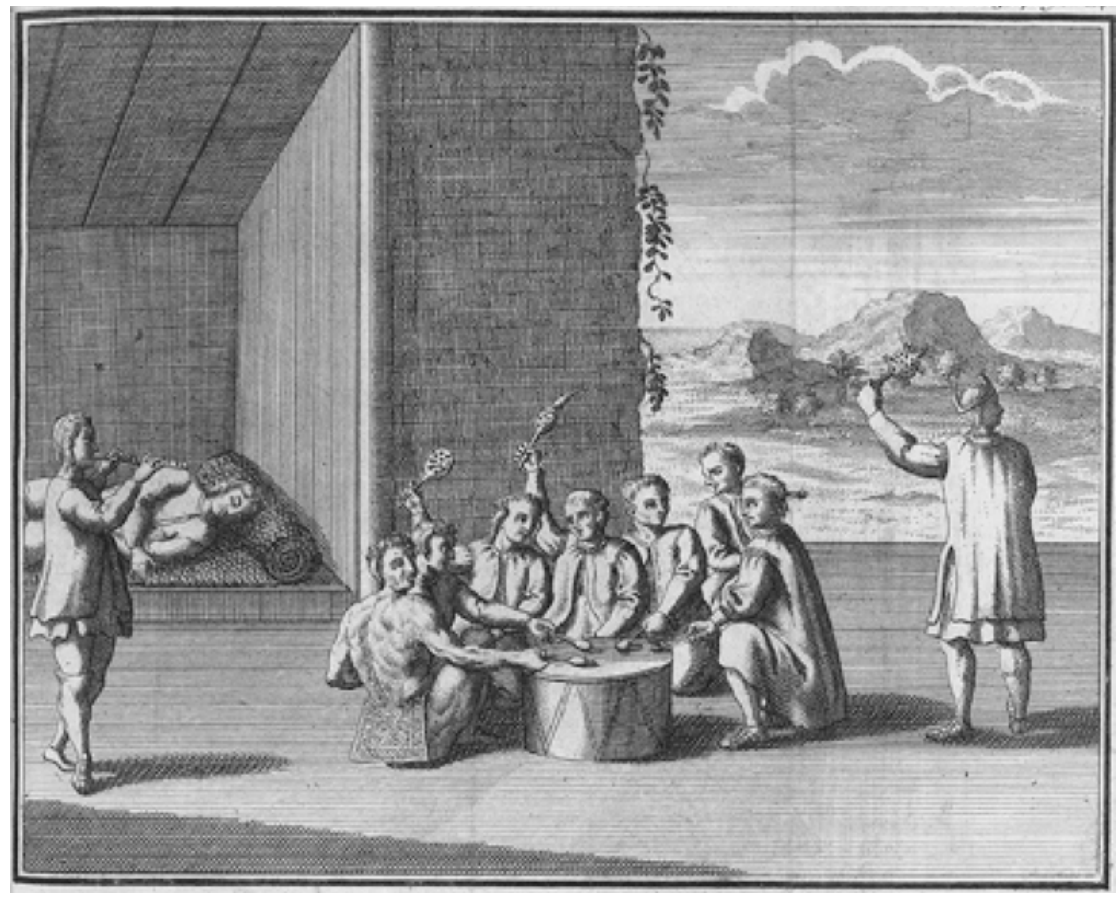

Image 7: M. de Bacqueville de la Potherie, Histoire de l'Amérique septentrionale, contenant le voyage du fort Nelson dans la baie d'Hudson, à l'extrémité de l'Amérique, le premier établissement des français dans ce vaste pays, la prise dudit fort de Nelson; la description du fleuve du Saint Laurent, le gouvernement de Québec, des Trois-Rivières et de Montréal, depuis 1534 jusqu'en 1701; l'histoire des peuples alliés de la Nouvelle-France, leurs mours et leurs maximes, et leurs intérêts avec toutes les nations des lacs Supérieurs, tels que sont les Hurons et les Illinois, l'alliance faite avec les Français et ces peuples, la possession de tous ces pays au nom du roi et tout ce qui s'est passé de plus remarquable sous MM. de Traci, de Frontenac, de La Barre et de Denonville, l'histoire des Iroquois, leurs mours, leurs maximes, leur gouvernement, leurs intérêts avec les anglais leurs alliés, tous les mouvements de guerre depuis 1689 jusqu'en 1701, leurs négociations, leurs ambassades pour la paix générale avec les français et les peuples alliés de la Nouvelle-France; l'histoire des Abénakis, la paix générale dans toute l'Amérique septentrionale sous le gouvernement de Monsieur de Frontenac et Monsieur le chevalier de Callières, pendant laquelle des nations éloignées de six cent lieues de Québec s'assemblèrent à Montréal: par Monsieur de Bacqueville de la Potherie, né à la Guadeloupe, dans l'Amérique Méridionale, aide-major de la dite isle, enrichie de figures (Paris, Nion et Didot, 1722), III : 24. The John Carter Brown Library at Brown University.

premier abord, quasi inexistant. Seules les illustrations de l'ouvrage de Bossu (image 18), publié en 1768, montrent un paysage nettement plus élaboré. Il est vrai qu’à cette époque, le paysage intéresse encore peu les peintres, en ce sens les graveurs se plient aux canons picturaux de l'époque. Une analyse plus précise de ces images permet cependant de 
faire ressortir d'autres éléments pour expliquer la présence ou l'absence de paysage.

En 1703, les images qui accompagnent les Nouveaux voyages du baron de Lahontan se caractérisent par l'absence totale de paysage ${ }^{32}$. Ces images présentent des Amérindiens dans des scènes de la vie quotidienne ou rituelle. L'absence de paysage s'explique par la nature schématique des gravures qui ressemblent plutôt à des esquisses. Les gravures de Lahontan suivent la méthode dite rotative: chaque image est subdivisée en plusieurs parties indiquant les différentes étapes du rituel. Des explications écrites accompagnent chacune d'entre elles, de telle sorte que l'écriture occupe une partie importante de l'image et prend la place que le paysage devrait occuper en arrière-plan. Par ailleurs, Lahontan s'intéresse assez peu à la nature, il semble normal que le paysage soit absent des gravures.

Dans les images de Lafitau (images 4 et 5), de Bacqueville de la Potherie (image 7), ou celles du graveur protestant Bernard Picart ${ }^{33}$ (image 6) dont les ouvrages paraissent au début des années 1720, plusieurs points communs sont à relever.

Toutes montrent un paysage quasi désertique suggérant l'immensité du continent, parsemé de quelques palmiers. La présence des palmiers surprend, ces images étant censées représenter des régions où cet arbre est absent. Lafitau a vécu à Sault Saint Louis et décrit les nations de l'Amérique septentrionale. La planche de Bernard Picart illustre un sacrifice à Quitchi-Manitou (image 6), une divinité de la nation Outaouais dans la région des Grands Lacs. Sur cette image, les palmiers côtoient les maisons longues - habitat traditionnel des peuples iroquoiens. Ce manque de réalisme illustre à nouveau le désintérêt de l'époque pour la représentation du paysage. La gravure de Bacqueville de la Potherie mettant en scène les divertissements des jeunes hommes (image 7) montre - elle aussi - les petites collines et les palmiers, alors qu'elle est censée représenter l'Amé-

32. Sur les gravures de Lahontan, voir les travaux de Réal Ouellet, entre autres, «Le discours des gravures dans les Voyages de Lahontan (1702-1703)», loc. cit., 31-48; R. Ouellet, "Une littérature qui se donne pour la réalité: la relation de voyage», dans Madeleine Frédéric et Serge Jaumain, La relation de voyage: un document historique et littéraire (Bruxelles, Presses de l'Université Libre de Bruxelles, 1999), 9-35.

33. J.-F. Bernard, Cérémonies et coutumes religieuses des peuples idolâtres, représentés par des figures dessinées de la main de Bernard Picart; avec une explication historique et quelques dissertations curieuses (Amsterdam, chez Jean-François Bernard, 1723-1728); sur les gravures de Picart, voir Frank Lestringant, «Le Roi Soleil de la Floride, de Théodore de Bry à Bernard Picart », Études de Lettres, «Mots et images nomades», 1-2, (janvier-juin 1995): 13-30. 
rique septentrionale. Cette image illustre un trait récurrent dans les gravures de Bacqueville: le soin pris par le graveur, dans les scènes d'intérieur, à représenter un paysage en le laissant entrevoir par une porte ouverte, ou par un autre stratagème. Cela montre que l'artiste accorde une certaine importance au paysage.

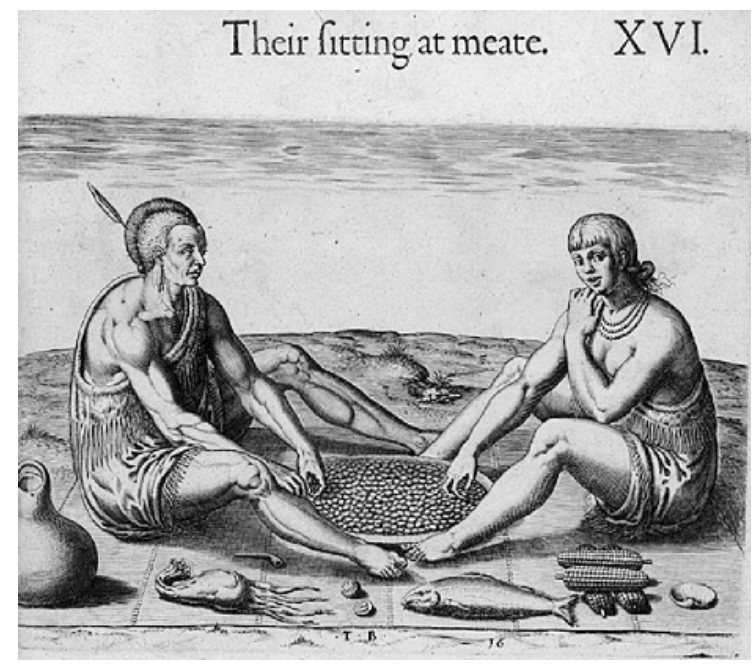

Image 8: «Their Sitting and Meate», gravure de Théodor de Bry d'après une aquarelle de John White; dans Thomas Harriot, A Briefe and True Report of the New Found Land of Virginia. Of The Commodities and of The Nature And Manners of the Natural Inhabitants... (Franckfort, 1590), planche XVI. The John Carter Brown Library at Brown University.

L'explication est peut-être que ce paysage possède une signification symbolique. Il s'inscrit en effet dans une tradition de représentation de l'Amérique qui remonte aux premiers temps de la Découverte. On retrouve ce paysage de désert dans les gravures de Théodor De Bry (image 8). Il symbolise dans l'esprit des Européens «l'exotique», le Nouveau Monde. Dans la littérature de voyage en Amérique, le palmier est au paysage ce que le cannibalisme est à la scène ethnographique. Il importe peu que le palmier ne pousse pas dans la région des Grands Lacs, sa présence est là pour signifier qu'il est question de «l'ailleurs». C'est sans doute ce qui explique le soin du graveur de Bacqueville à ajouter un paysage à des scènes d'intérieur: il joue le rôle d'un symbole permettant au lecteur de situer l'action représentée. La question du palmier renvoie au problème du vrai et du vraisemblable. Le vraisemblable s'inscrit toujours dans un 
système de conventions qui permettent de reconnaître le sujet représenté. Il évolue donc en fonction des époques, des cultures et des genres picturaux. Le lecteur européen du $\mathrm{xvIII}^{\mathrm{e}}$ siècle sait décrypter les codes de représentation utilisés par les graveurs et ne s'étonne pas de la présence de palmiers.

La récurrence du caractère épuré du paysage peut aussi s'expliquer par des raisons techniques. Comme l'a suggéré Réal Ouellet, le graveur par souci de clarté offre une image épurée du paysage afin de mettre en évidence l'action représentée ${ }^{34}$. Il convient de prendre en considération les contraintes imposées par les méthodes de la taille-douce et de la gravure sur bois de bout qui limitent considérablement les capacités d'expression du graveur ${ }^{35}$. L'impression en noir l'empêche d'apporter certaines nuances et rend difficile la représentation de certains détails comme la neige. Il convient de prendre en compte également le facteur économique. Les gravures étaient très coûteuses, particulièrement celles qui étaient réalisées suivant la technique de la taille-douce. C'est pourquoi on reprenait souvent d'anciennes planches afin de réduire les coûts de production. C'est sans doute ce qui explique le fait que, dans les gravures de Bernard Picart, on retrouve le même paysage de collines et de palmiers qui a servi à illustrer la cérémonie à Quitchi-Manitou (image 6, ci-dessus), ainsi que d'autres rituels se déroulant sur l'île Espagnola, à Mexico, ou encore dans les Caraibes (images 9,10 et 11). Le même décor sert d'arrière-plan à un rituel funéraire au Pérou et à une procession de Ganga en Inde (images 12 et 13).

34. R. Ouellet, «Le discours des gravures dans les Voyages de Lahontan (1702-1703)», loc. cit., 36.

35. Sur les techniques de gravure voir Jacques Forge, «Naissance d'une image», dans Michèle Duchet, dir., L'Amérique de Théodore de Bry. Une collection de voyages protestante du XVI siècle. Quatre études d'iconographie (Paris, Éditions du CNRS, 1987), 106-107; voir aussi Jean-Eugène Bersier, La gravure: les procédés, l'histoire (Paris, Berger-Levrault, 1984). 


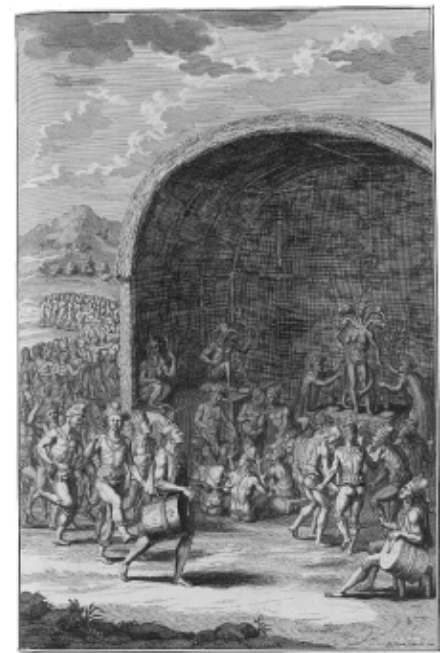

Image 9

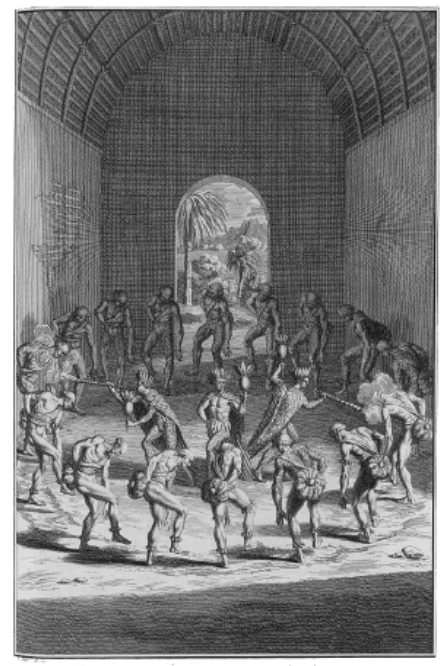

Image 11

Images 9 à 13: Gravures de Bernard Picart, dans J.-F. Bernard, op. cit., image $9, \mathrm{I}, 1: 142$; image $10, \mathrm{I}, 1: 156$; image $11, \mathrm{I}, 1: 174$; image 12, I,1:206; image 13, I,2 : 138. The John Carter Brown Library at Brown University.

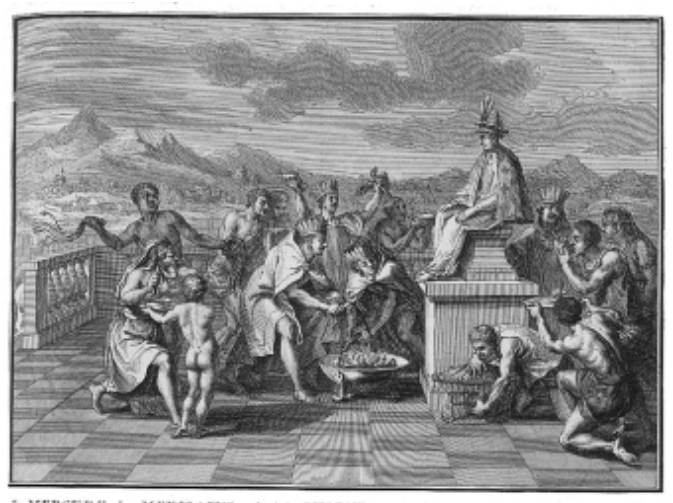

Image 10

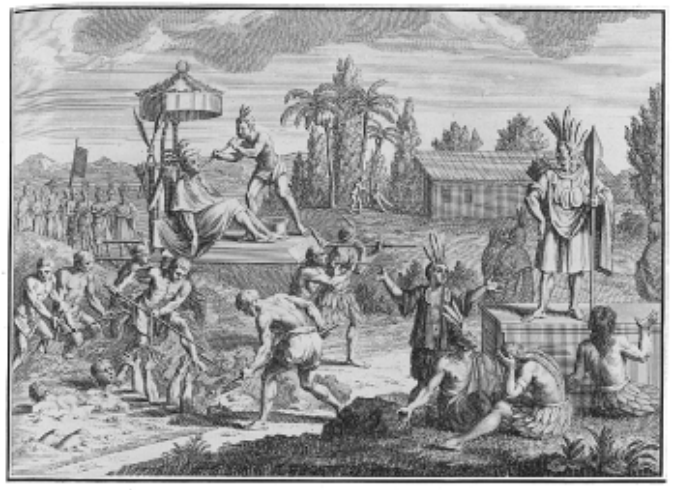

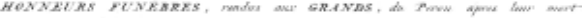
Image 12

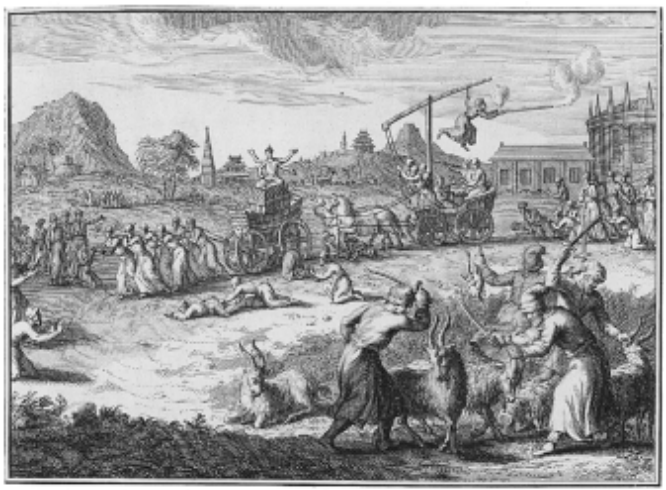

Image 13 
En comparaison de ces images de la Nouvelle-France, les peintures du Brésil du peintre hollandais Albert Eckhout, réalisées au milieu du XvII siècle, offrent un contraste saisissant ${ }^{36}$ (images 14 et 15).

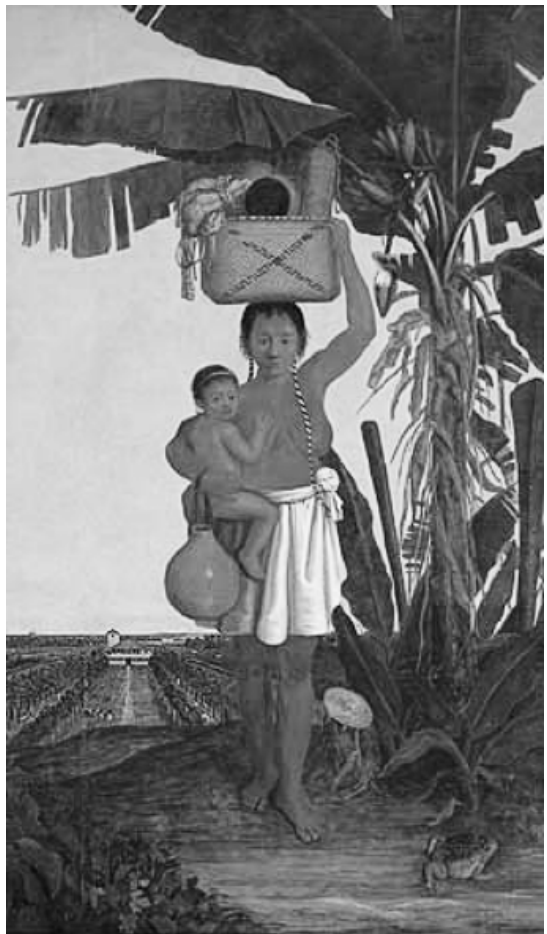

Image 14: Albert Eckhout, Femme

Tupinamba (1641), huile sur toile,

274 x $163 \mathrm{~cm}$. Département d'ethnographie, Musée national de Copenhague.

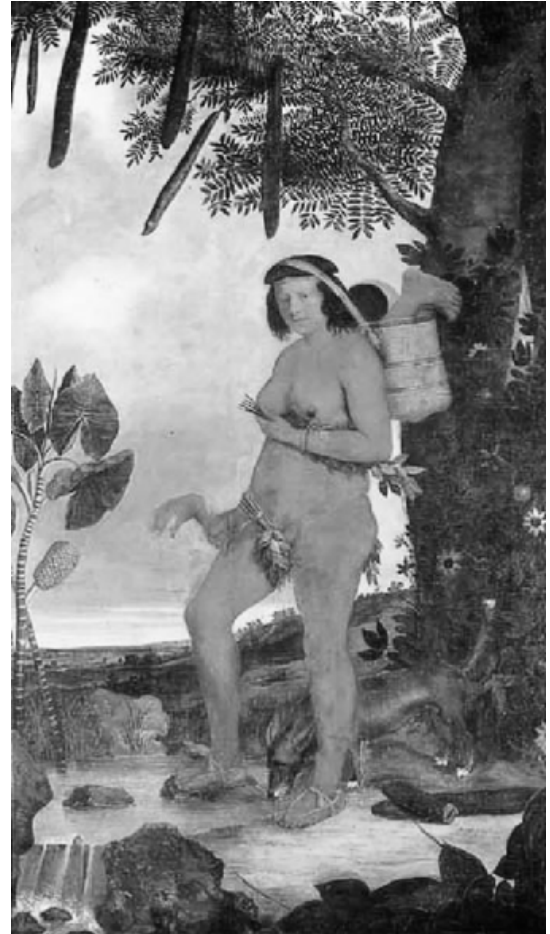

Image 15 : Albert Eckhout, Femme Tapuya (1641), huile sur toile, $266 \times 159 \mathrm{~cm}$. Département d'ethnographie, Musée national de Copenhague.

Source: http:/ / eckhout.natmus.dk/gallery.shtml (consulté le 9 septembre 2005).

Elles se caractérisent par la précision et la richesse des détails ainsi que par le réalisme dans la figuration des corps et de la nature, ce qui est exceptionnel pour l'époque. Le contexte dans lequel ces œuvres ont été réalisées l'est tout autant. Albert Eckhout a participé à une expédition scientifique au Brésil mandatée par le gouverneur Johan Maurits Van 
Nassau-Siegen. Il y a séjourné pendant deux ans. Il prend un très grand soin à peindre le paysage comme l'atteste le dessin de la plantation qui figure en arrière-plan du tableau de la femme Tupinamba (image 14). Les détails de la faune et de la flore sont très précis. La précision de ces images explique qu'elles aient postérieurement servi de modèle à des artistes européens pour illustrer des tapisseries et des objets de porcelaine. Nous sommes donc face à deux contextes de production d'images radicalement distincts. Dans le cas des graveurs de la Nouvelle-France, les artistes travaillent à partir de descriptions et se conforment à des codes picturaux propres aux récits de voyage, alors que dans le cas d'Eckhout, le peintre a vécu sur place pendant plusieurs années et a le souci de peindre d'après nature. La comparaison permet de mettre en évidence l'importance majeure des acteurs et de l'expérience du pays représenté dans la réalisation des images ${ }^{37}$.

Les gravures réalisées au milieu du siècle en Nouvelle-France font ressortir plusieurs nouveautés. Le palmier a totalement disparu. Celles de
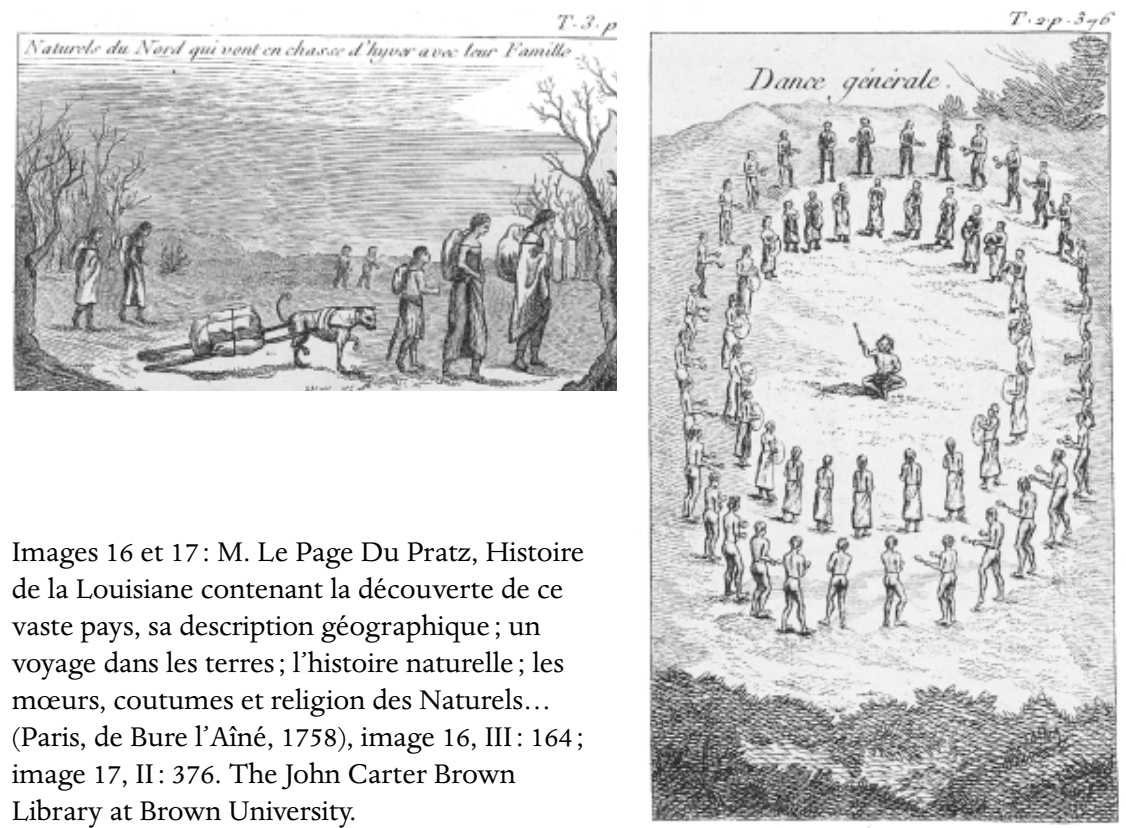

Images 16 et 17 : M. Le Page Du Pratz, Histoire de la Louisiane contenant la découverte de ce vaste pays, sa description géographique; un voyage dans les terres; l'histoire naturelle; les mœurs, coutumes et religion des Naturels... (Paris, de Bure l'Aîné, 1758), image 16, III : 164; image 17, II : 376. The John Carter Brown Library at Brown University.

37. Ces images circulaient en Europe à la même époque : l'œuvre d'Eckhout a été disséminée dans différents pays européens et une partie a été léguée à Louis XIV; sur l'interprétation de l'œuvre d'Albert Eckhout, voir R. Joppien, «The Dutch Vision of Brazil», dans Ernst Van Den Boogaart, dir., Johan Maurits Van Nassau-Siegen 1604-1679. Essays at the Occasion of the Tricentenary of his Death (The Hague, The Johan Mauritz van Nassau Stichting, 1979), 297-377. 
l'ouvrage de Le Page Du Pratz (images 16 et 17), qui parait à Paris en 1758, semblent plus proches des gravures de la période précédente: le désert persiste mais de façon beaucoup plus épurée qu'auparavant. Dans l'image d'une famille de Canzès partant à la chasse l'hiver, le paysage y est quasiment inexistant (image 16).

Le même paysage très épuré se répète sur la gravure représentant une danse générale chez les Natchez pendant la grande fête du blé. Nous devinons que la scène se déroule à l'extérieur grâce aux buissons à l'avantplan (image 17). L'accent est plutôt mis sur les détails ethnographiques et sur le corps, aspects sur lesquels je reviendrai. Dans les iconographies accompagnant la relation de Bossu (image 18), le paysage est plus riche, plus détaillé et semble plus réaliste: la forêt et les fleuves sont présents. Cette image, réalisée au milieu du siècle, coïncide avec le goût naissant pour une esthétique naturelle qui aboutira à la fin du XviII à la perception romantique de la nature ${ }^{38}$. Le graveur de Bossu exprime peut-être la vision romantique pour la colonie perdue.

Image 18: Jean-Bernard Bossu, Nouveaux voyages aux Indes Occidentales; contenant une relation des différents peuples qui habitent les environs du grand fleuve Saint-Louis, appelé vulgairement le Mississippi, leur religion; leur gouvernement; leurs mours; leurs guerres et leur commerce (Paris, Le Jay, 1768); frontispice. The John Carter Brown Library at Brown University.

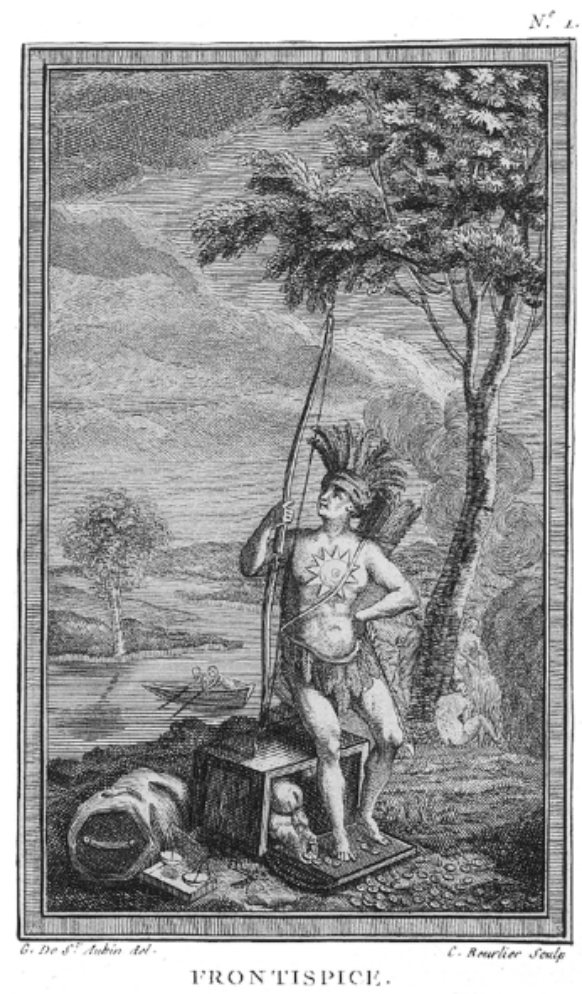

38. François Walter, Les Suisses et l'environnement..., op. cit., 46-51. 
À l'exception du cas de Bossu qui reproduit davantage l'idée d'une nature généreuse, on remarque un contraste saisissant entre les descriptions littéraires et les images. Le désert est prédominant dans la majorité des gravures. Ces dernières ne servent donc pas à montrer les richesses naturelles de la Nouvelle-France, l'idéalisation comme projection des désirs impérialistes semble inexistante dans les gravures, ce qui ne signifie cependant pas que ces images soient dénuées de tout usage propagandiste. La propagande coloniale, dans les images, peut utiliser d'autres canaux que celui du paysage. J'y reviendrai. L'appropriation (ou la négation) symbolique du paysage se traduit par son idéalisation (ou sa dépréciation), mais aussi par la "connaissance», par cet épistémè qui ordonne, compare, représente et qui, selon Michel Foucault, est propre à l'époque classique $^{39}$.

\section{2 - CONNAÎTRE L'ESPACE ET PRENDRE POSSESSION DU TERRITOIRE}

Les récits de voyage jouent un rôle vital pour Versailles: le témoignage des voyageurs permet de dresser un inventaire des ressources à exploiter. Cet objectif est clair dans l'ouvrage de Dumont de Montigny ${ }^{40}$, ingénieur, lieutenant et planteur qui vécut en Louisiane de 1719 à 1737. Dumont entend décrire cette "grande et belle province ${ }^{41}$ ». Son intention d'inventorier les richesses se reflète aussi dans le plan du livre: la première partie porte sur l'histoire naturelle de la Louisiane (le climat, les terres, la faune, la flore, les cultures potentielles) à laquelle est annexée la section sur les Amérindiens. La deuxième partie de l'ouvrage raconte chronologiquement l'histoire de la colonie. Le pragmatisme de l'auteur transparaît également dans les gravures accompagnant le récit, et particulièrement dans le "plan du fort Rozalie des Natchez et de ses environs" (image 19).

Le fait de représenter un espace restreint - un fort - montre le désir de Dumont de décrire les infrastructures de la colonie et lui permet également de mettre en évidence certains détails qu'une échelle plus grande aurait ignorés : l'accès au fleuve, la localisation des nations amérindiennes et les ressources disponibles dans les environs du fort (les champs cultivés

39. Claude Reichler, «Un texte est un migrant. L’exemple d'une relation jésuite écrite en 1636», Études de lettres, 2 (2001): 115 ; Michel Foucault, Les mots et les choses (Paris, Gallimard, 1966).

40. Dumont de Montigny, Mémoires historiques sur la Louisiane, contenant ce qui est arrivé de plus mémorable depuis l'année 1687, jusqu'à présent; avec l'établissement de la colonie française dans cette province de l'Amérique Septentrionale... (Paris, C. J. B. Bauche, 1753).

41. Ibid., I: 2. 


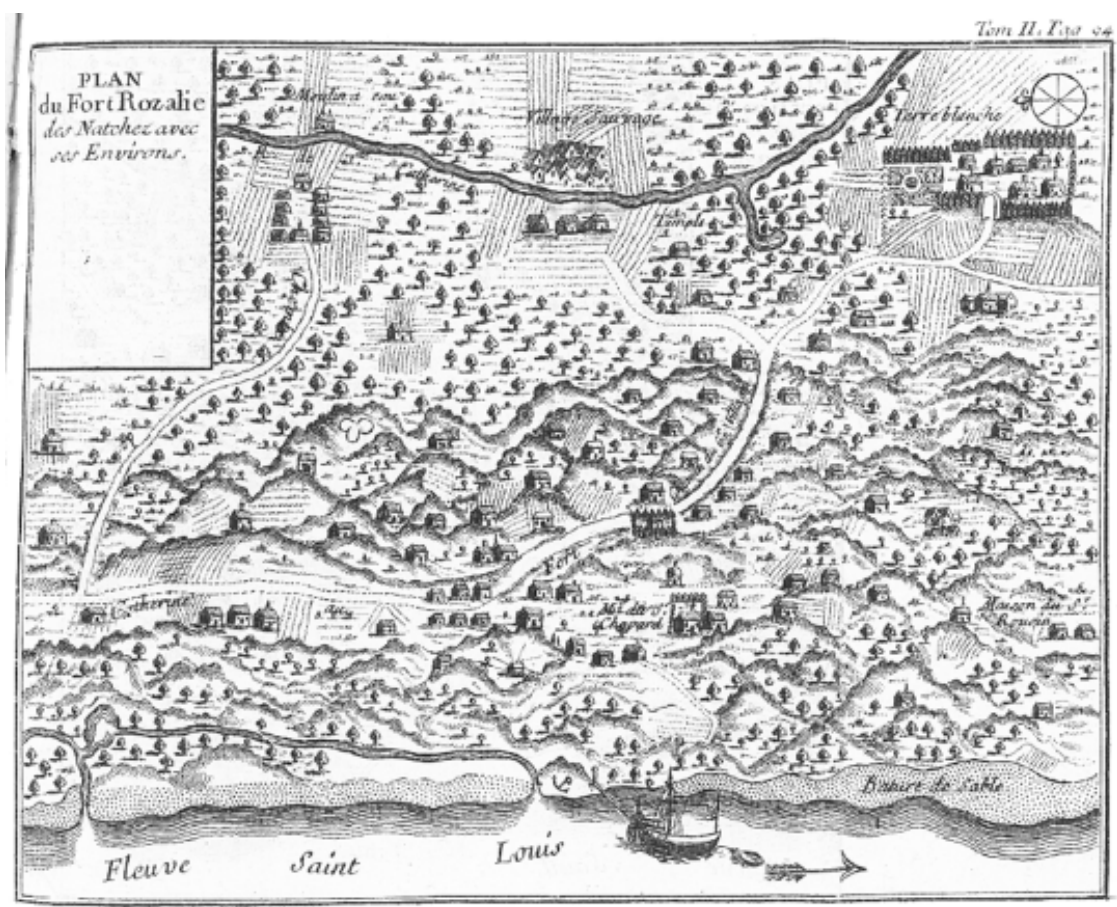

Image 19: «Plan du Fort Rozalie des Natchez et de ses environs». Dumont de Montigny, Mémoires historiques sur la Louisiane, contenant ce qui est arrivé de plus mémorable depuis l'année 1687, jusqu'à présent; avec l'établissement de la colonie française dans cette province de l'Amérique Septentrionale... (Paris, C. J. B. Bauche, 1753), II : 94. The John Carter Brown Library at Brown University.

et les forêts). La densité des forêts sur la carte illustre l'idée de la profusion du bois de chauffage. La carte permet de représenter graphiquement les richesses de la colonie. Elle exprime la vision du colonisateur: elle donne l'image d'un paysage cultivé, policé, ordonné, ce qui répond à la volonté de Dumont de Montigny de prouver que les terres des Natchez sont les meilleures que les Français «puissent se glorifier d'avoir ${ }^{42}$ ».

L'utilisation politique de la carte apparaît aussi chez Lahontan dans l'exemple de la carte de la Rivière Longue ${ }^{43}$ (image 20). Cette carte a fait

42. Ibid., II : 61 .

43. D’après Réal Ouellet et Alain Beaulieu, il s'agit de la rivière Minnesota. Le nom « rivière Longue" serait peut-être la traduction française de Ohan Haska Wakpa, nom Dakota pour la rivière Sainte-Croix; Lahontan, Euvres complètes, op. cit., 383. 


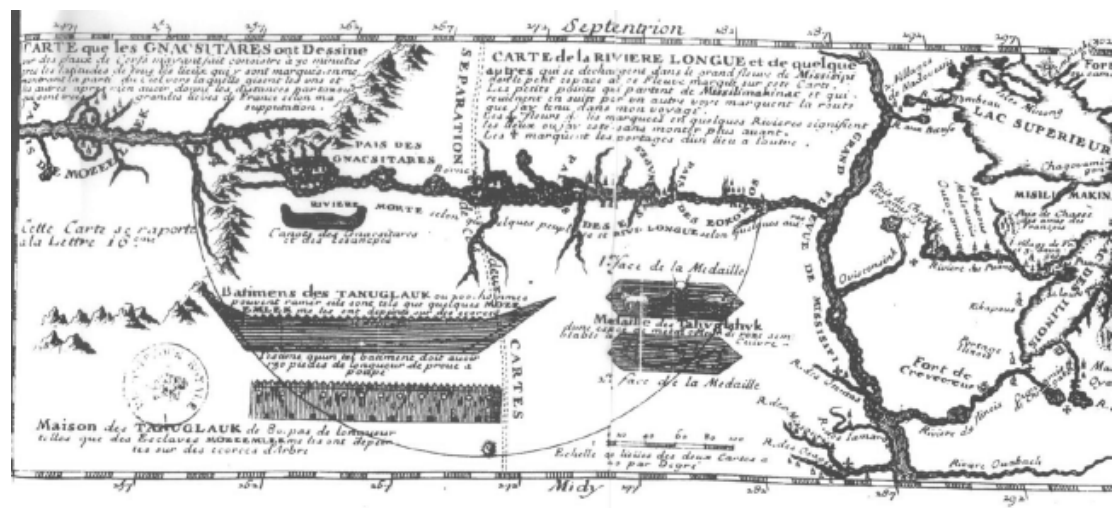

Image 20: Carte de la Rivière Longue; Louis Armand de Lom d'Arce, Baron de Lahontan, op. cit

l'objet de multiples controverses que je n'aborderai pas, mon but étant simplement d'étudier les représentations transmises par le baron libertin ${ }^{44}$. Cette carte rassemble les connaissances françaises, les informations collectées par Lahontan lors de son supposé voyage dans cette région et celles fournies par les autochtones à propos des régions encore inexplorées. Les fleuves occupent une grande partie de l'espace de la carte; leur largeur est exagérée par rapport à l'échelle afin de les mettre en relief. Les fleuves sont des axes de communication essentiels pour assurer le contrôle du territoire militairement et commercialement. Leur importance est accentuée par la représentation de deux canots, mode de transport fluvial privilégié dans cette région. La carte signale l'emplacement des nations alliées et des territoires de chasse, indications précieuses pour voyager en terre indienne ${ }^{45}$. Cette carte a donc une fonction stratégique. Elle joue, comme les insulaires étudiés par Frank Lestringant, un double rôle de mémoire et de matrice: "elle enregistre les acquis de l'expérience française au Nouveau Monde» et témoigne aussi du "désir d'espace" 46 ".

On relève également une attention très grande à nommer les lieux en conservant les noms indigènes ou en les francisant. Renommer les lieux

44. Sur cette controverse, voir Judith Chamberlin Neave, «Lahontan and the Long River Controversy ", Revue de l'Université d'Ottawa, 48,1-2 (janvier-avril 1978): 124-147.

45. La carte est alors "guide et mentor de l'explorateur"; voir Numa Broc, La géographie de la Renaissance (Paris, CHTS, 1986).

46. Frank Lestringant, Le livre des îles : atlas et récits insulaires de la Genèse à Jules Verne (Genève, Droz, 2002), 185; François Wahl, "Le désir d'espace», Cartes et figures de la terre (Paris, Centre Georges Pompidou, 1980), 41-46. 
par des appellations françaises rappelle le fait que les missionnaires rebaptisaient leurs ouailles en leur donnant des noms chrétiens. Christianiser le nom amérindien était un moyen de gommer l'identité autochtone. Selon Denys Delâge, cette pratique des jésuites signifiait «symboliquement [...] la dépossession d'une tradition, d'une appartenance, d'une identité. Aspirant à la détention exclusive du pouvoir religieux, les jésuites s'approprient le pouvoir de nommer ${ }^{47}$.» $\mathrm{Si}$ "nommer», signifie "prendre» ou marquer une appropriation, «renommer» les lieux est une façon de déposséder les autochtones de leur territoire. La toponymie constitue une forme d'appropriation du territoire par le langage ${ }^{48}$. Elle permet de gommer l'altérité en singularisant les lieux, d'en prendre possession en les faisant entrer dans la mémoire ${ }^{49}$ et en les inscrivant dans une fiction politique. La carte est ainsi, comme l'a suggéré Brian Harley, une arme impériale ${ }^{50}$.

Plusieurs types de frontières se superposent sur la carte de Lahontan: une frontière épistémologique, séparant les territoires explorés et inexplorés, est matérialisée sur la carte par l'indication «séparation des deux cartes "; les frontières commerciales sont délimitées par les mentions du type: "pays de chasse des amis des Français»; et enfin des frontières propres aux autochtones s'expriment par la division en "pays» portant le nom des nations qui les occupent.

L'organisation de la carte illustre l'appropriation stratégique du territoire par le biais de la connaissance et de la représentation. Elle exprime graphiquement, d'une part, l'emprise impériale sur cette région et, d'autre part, la volonté de connaître les espaces géographique, commercial et politique, afin de mieux les contrôler. La représentation de plusieurs types de frontières et la présence côte à côte de noms amérindiens et de noms français

47. Denys Delâge, Le pays renversé. Amérindiens et Européens en Amérique du Nord-Est 1600-1664 (Montréal, Boréal, 1991), 203.

48. Pour Jacques Derrida, la toponymie est «l'acte de violence le plus absolu. Donner un nouveau nom qu'il sera éventuellement interdit de prononcer, telle est la violence originaire du langage »; Jacques Derrida, «La violence de la lettre: de Lévi-Strauss à Rousseau », De la grammatologie (Paris, Minuit, 1967), 164.

49. D'après Jean-Luc Piveteau, le territoire prend forme "autour de cette rencontre entre l'espace et le temps qui se cristallise notamment dans les toponymes, noms donnés aux lieux pour les faire sortir de leur anonymat, les singulariser, et ainsi les faire entrer dans la mémoire et dans une histoire», cité par Béatrice Collignon, «Les toponymes inuit. Mémoire du territoire. Étude de l'histoire des Innuinait ", Anthropologies et Sociétés, 26,2-3, (2002): 45-46.

50. Pour Brian Harley, la carte est une forme de discours fonctionnant comme un langage. En analysant l'organisation de l'image, le titre, la décoration et les silences de la carte, il est possible de voir comment elle a "force de loi dans le paysage»; Brian Harley, "Maps, Power and Knowledge", dans D. Cosgrove, D. Daniels, dir., The Iconography of Landscape. Essays on the Symbolic Representation... (Cambridge, Cambridge University Press, 1988), 277-312. 
reflètent la réalité de l'implantation française dans cette région: le contrôle du territoire n'est assuré que par quelques forts et par des réseaux d'alliance dont la stabilité est incertaine. La faible implantation démographique des Français et l'inconstance des nations alliées ajoutées à la menace britannique poussent les Français à s'engager dans une politique de cadeaux coûteuse pour conserver leurs alliés amérindiens. Comme l'a montré Gilles Havard, le Pays d'en Haut est une terre indienne ${ }^{51}$. Nous pouvons donc en déduire que si la carte constitue une arme d'empire, servant à la fois de mémoire et de projection, elle est aussi le reflet d'une réalité politique: celle de la nécessité de l'alliance avec les autochtones. Cet exemple confirme l'hypothèse de Frank Lestringant selon laquelle la réalité préexiste à la représentation ${ }^{52}$.

Il convient maintenant de se demander comment, dans une telle vision pragmatique du paysage, le corps amérindien y est intégré et de quelle façon la relation entre les autochtones et leur milieu est perçue par les voyageurs. Est-elle - elle aussi - instrumentalisée? Et, si le paysage n'existe pas ou presque pas dans les images, qu'en est-il du corps?

\section{3 - LA PLACE DU CORPS AMÉRINDIEN DANS LE PAYSAGE}

Les voyageurs relèvent unanimement la parfaite adaptation du corps amérindien au milieu. Ils sont frappés, notamment, par l'habileté des Indiens à se repérer dans l'espace et à reconnaître les traces des animaux et des hommes sur n'importe quel type de sol. Lahontan évoque leur aptitude à «traverser les forêts de cent lieues en droiture sans s'égarer; à suivre les pistes d'un homme ou d'une bête sur l'herbe et sur les feuilles ${ }^{53}$ ». Pierre Pouchot - un des officiers de Montcalm qui servit dans la région des Grands Lacs pendant la Guerre de Sept Ans - semble admiratif de l'aptitude des Amérindiens à identifier les empreintes des hommes et des animaux:

leur sagacité à découvrir toute sorte de trace est singulière: la terre foulée, les feuilles renversées, la rosée abattue, tout cela ne les empêche pas de reconnaître les pistes des fauves. Les pieds des sauvages se connaissent par l'espèce de chaussure, mais surtout par la façon dont le pied est placé et tourné. Ils jugent encore plus aisément si ce sont des Européens, au pas et à la semelle.

51. Gilles Havard, Empires et métissages. Indiens et Français dans le Pays d'En Haut (Québec, Septentrion, 2003).

52. Frank Lestringant, Le livre des îles..., op. cit.

53. Lahontan, Euvres complètes, op. cit., 647-648, 714. 
Ils distinguent même un Anglais d'un Français, et devinent assez juste combien il y a de monde, soit par les traces soit par les feux qu'ils ont allumés et par les couchées, si ces traces sont d'un parti en campagne ${ }^{54}$.

Les voyageurs sont également étonnés par la capacité des autochtones à résister au froid. L'explorateur Henri de Tonti écrit à la fin du XviI ${ }^{\mathrm{e}}$ siècle à propos des Indiens des Grands Lacs et du Mississipi : «Leurs corps sont accoutumés et endurcis à toutes les injures de l'air ${ }^{55}$." Selon un auteur anonyme qui a voyagé au début du $\mathrm{xvIII}^{\mathrm{e}}$ siècle, les Indiens du Canada «sont infatigables, ils supportent avec une patience vraiment héroïque, toutes les infirmités auxquelles la nature humaine est sujette, de même que le froid excessif et la trop grande chaleur, sans que jamais on les entende proférer aucune plainte ${ }^{56} \%$. D’après Jean-Bernard Bossu, cette résistance physique au froid viendrait de leur éducation:

Ils élèvent très durement leurs enfants, les font baigner et nager dans l'hiver dès la pointe du jour. Les enfants à la mamelle sont baignés en hiver dans l'eau froide, et lorsqu'ils deviennent grands, on les fait coucher sur la dure. Comme les sauvages aiment beaucoup leurs enfants, c'est par cette raison qu'ils les accoutument de bonne heure à la fatigue; ils disent aussi que l'habitude est une seconde nature. Il est vrai que leur corps qui est nu n'est pas plus sensible au froid que le visage et les mains ${ }^{57}$.

Bossu insinue que la résistance du corps n'est pas naturelle mais culturelle. Par cette remarque, il corrobore l'idée - dominante à l'époque - que les Amérindiens ont la même origine que les Européens. Cette idée s'appuie sur la philosophie naturaliste qui consiste à expliquer l'origine de la

54. P. Pouchot, Mémoires sur la dernière guerre de l'Amérique Septentrionale entre la France et l'Angleterre... (Yverdon, 1781), III : 345 ; voir aussi P. F.-X. Charlevoix, Histoire et description générale..., op. cit., III : 239 ; voir également Lamothe-Cadillac, Relation du Sieur de Lamothe-Cadillac..., op. cit., V: 92; et aussi, Joseph François Lafitau, Mœurs des sauvages ameriquains comparées aux moeurs des premiers temps (Paris, Chez Saugrain l'Aîné, Charles-Estienne Hochereau, 1724), II : 244-245, III: 239.

55. Chevalier de Tonti, Relations de la Louisiane, et du fleuve Mississippi, Par le chevalier de Tonti, gouverneur au fort saint louis, aux Illinois, d'après Barbier (Amsterdam, J.-F. Bernard, 1720), 48.

56. Chevalier de ${ }^{\star \star \star}$, Voyages et aventures $d u$ Chevalier de ${ }^{\star \star \star}$ (Londres et Paris, Cassain, 1769), 172.

57. J.-B. Bossu, Nouveaux voyages aux Indes Occidentales..., op. cit., II : 24 ; Dumont de Montigny est lui aussi impressionné par la résistance au froid des Amérindiens: «ils doivent être endurcis au froid: aussi ne l'appréhendent-ils nullement; on les voit, même dans des gelées assez fortes, hommes, femmes et enfants aller dès la pointe du jour se baigner dans la rivière, pour se rendre plus durs et plus insensibles», Dumont de Montigny, Mémoires historiques sur la Louisiane..., op. cit., I: 141. 
diversité humaine non pas par les traits corporels de tel ou tel groupe ethnique, mais par l'environnement physique. Selon cette théorie, les Amérindiens vivant sous la même latitude que les Français auraient la même origine que ces derniers ${ }^{58}$. Les observateurs s'attachent donc à expliquer les différences physiques entre les uns et les autres par des motifs culturels: ici, l'éducation. C'est parce que les parents ont pour habitude de baigner leurs enfants très jeunes que le corps possède cette capacité à résister au froid. Par cette assertion, Bossu sous-entend peut-être un autre argument: si le corps amérindien s'adapte aux rigueurs de l'hiver, il en sera de même pour les futurs colons.

L'idée de la résistance au froid se traduit dans les gravures par une incohérence se répétant dans plusieurs textes: il s'agit de la nudité du corps dans des scènes se déroulant en hiver. Le graveur de Lahontan commet cette erreur sur l'image montrant un Amérindien nu chaussé de raquettes - mode de transport hivernal (image 21). Dans l'édition contrefaite de cette édition parue la même année, le graveur a pris le soin, par pudeur ou réalisme peut-être, de vêtir le personnage d'un brayer - vêtement d'été (image 22). Plusieurs éléments laissent penser que cette erreur ne choquait pas les contemporains, du moins si l'on en juge par les diverses réutilisations dont l'image fut l'objet postérieurement. On la retrouve en effet dans le Recueil de voyages au Nord de C. Bernard, publié lui aussi à Amsterdam entre les années 1715 et $1738^{59}$ (image 23), ainsi que dans L'atlas géographique, d'Henri Abraham Châtelain, publié à Amsterdam en $1732^{60}$ (image 24).

Cette erreur se reproduit dans la gravure de Lafitau représentant un campement d'hiver: tous les personnages sont vêtus d'un brayer malgré leurs activités hivernales (image 4). Lafitau relève lui-même cette erreur du graveur en commentant l’image: «le graveur a oublié de les envelopper

58. Selon cette théorie, les hommes sont potentiellement les mêmes, et ils ne se différencient qu'à l'âge adulte en fonction du milieu culturel et physique dans lequel ils évoluent. La philosophie naturaliste expliquait également que les facteurs climatiques créaient des variations corporelles; Joyce E. Chaplin, «Natural Philosophy and an Early Racial Idiom in North America: Comparing English and Indian Bodies", The William and Mary Quarterly, Third Series, LIV,1 (January 1997): 229-252.

59. J.-F. Bernard, Recueil de voyages au nord, contenant divers mémoires très utiles au commerce et à la navigation (Amsterdam, 1715-1738).

60. Henri Abraham Chatelain, Atlas historique ou nouvelle introduction à l'histoire ancienne \& moderne; représentée dans de nouvelles cartes, où l'on remarque l'établissement des états \& empires $d u$ monde, leur durée, leurs chutes, \& leurs différents gouvernements; la chronologie des consuls romains, des Papes, de empereurs... (Amsterdam, Chez Zacharie Chatelain, 1720-1739). 

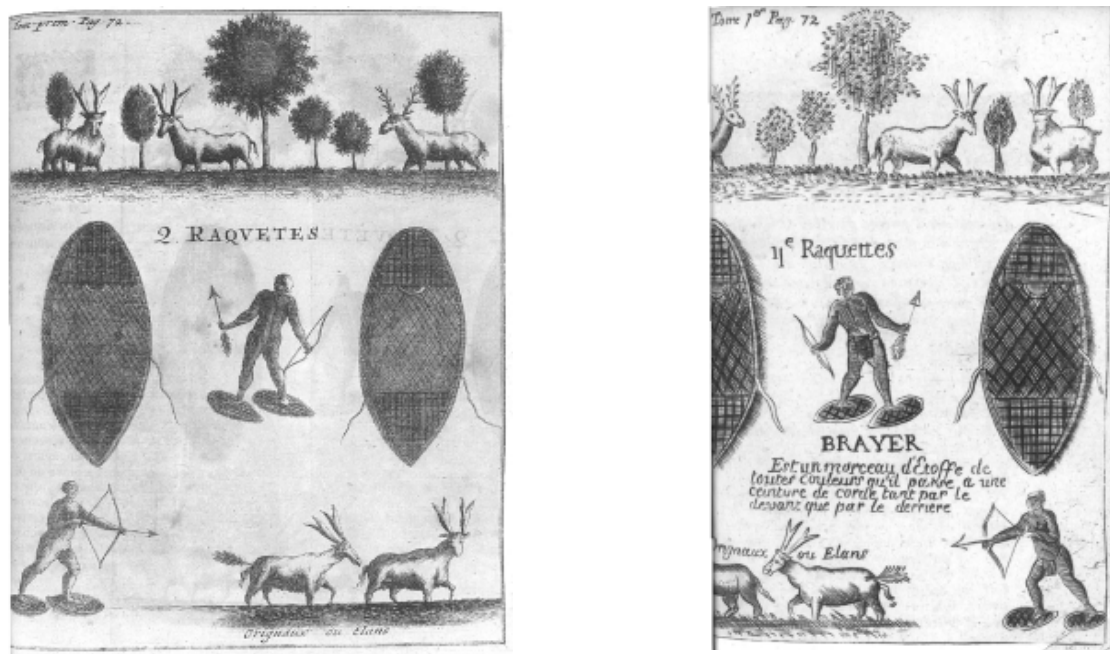

Images 21 et 22 : Ces deux images proviennent de deux exemplaires de la même édition du récit de voyage de Lahontan, l'une véridique, l'autre contrefaite. L'image 22 vient de l'édition contrefaite (chacune a le même emplacement dans le livre); Louis Armand de Lom d'Arce, Baron de, op. cit., I: 72. The John Carter Brown Library at Brown University.

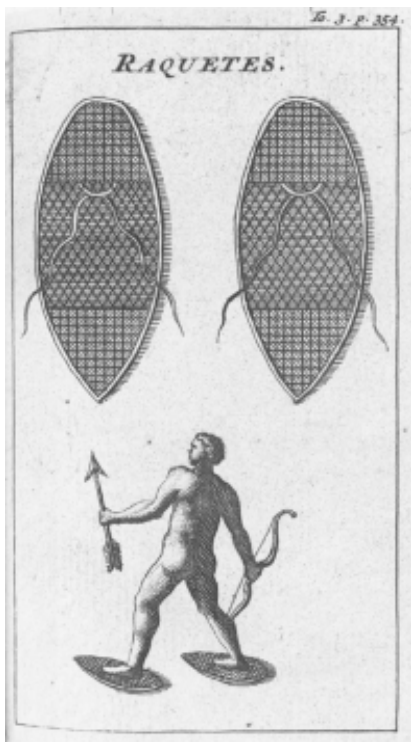

Image 23 : J.-F. Bernard, Recueil de voyages au nord, contenant divers mémoires très utiles au commerce et à la navigation (Amsterdam, 17151738), III : 354. The John Carter Brown Library at Brown University.

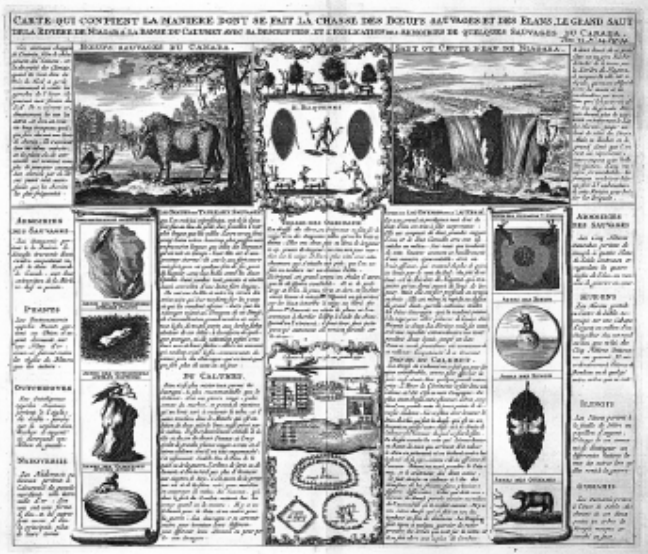

Image 24: Agrandissement tiré de Henri Abraham Chatelain, Atlas historique ou nouvelle introduction à l'histoire ancienne \& moderne; représentée dans de nouvelles cartes, où l'on remarque l'établissement des états \& empires du monde, leur durée, leurs chutes, \& leurs différents gouvernements; la chronologie des consuls romains, des Papes, de empereurs... (Amsterdam, Chez Zacharie Chatelain, 1720-1739); J.-F. Bernard, Recueil de voyages au nord, contenant divers mémoires très utiles au commerce et à la navigation (Amsterdam, 1715-1738); suit la page 94. The John Carter Brown Library at Brown University. 
[les Amérindiens] de leurs fourrures, ainsi que la saison le demande ${ }^{61}$ ». Cette incohérence semble perdurer: on la retrouve également dans un des premiers films des Frères Lumières, tourné en 1898, à Kahnawake ${ }^{62}$, mettant en scène une danse Mohawk. Le film reproduit la vision ethnocentriste européenne en réutilisant plusieurs clichés. Le premier est la présence, en arrière-plan, du tipi - habitat des Indiens des Plaines - alors que les Mohawks vivaient dans des maisons longues. Une paire de raquettes est accotée au tipi, ce qui surprend en raison de l'absence de neige. Ce que suggèrent ces exemples, c'est que la nudité, les raquettes ainsi que le brayer constituent des symboles de l'indianité. Ils permettent de reconnaître l'univers culturel dans lequel on se trouve. Le corps, quant à lui, est anonyme: il pourrait aussi bien être européen qu'amérindien. Ce sont les objets qui permettent de l'identifier. D’où leur présence quasi constante, y compris dans les scènes se déroulant en hiver.

Les images présentant des Indiens nus chaussés de raquettes sont sans doute le reflet de l'idée très répandue de la résistance au froid du corps amérindien. Elles montrent également la persistance de l'archétype de la nudité, suggérant que même l'hiver, les Amérindiens iraient nus. L'origine de cet archétype remonte aux premières représentations de l'Amérique. Dans la première lettre que Colomb écrit au roi et à la reine d'Espagne, il écrit que «les hommes et les femmes vont presque nus ${ }^{63}$ ». La gravure de Johann Froschauer, illustrant un groupe de Tupinambas, accompagne une des premières éditions de cette lettre (image 25). Cette scène fixe le modèle de représentation européenne de l'Amérique pour plusieurs siècles. La scène de cannibalisme devient un thème récurrent de la littérature de voyage, au même titre que la couronne de plumes, la nudité et l'attitude des personnages rappelant la statuaire grecque. L'Antiquité était en effet le seul référant pictural dont disposaient les artistes de la Renaissance pour représenter la nudité des autochtones décrite dans les premiers écrits européens. La nudité fut ensuite généralisée à toutes les nations amérindiennes, y compris à celles vivant dans des climats plus froids comme les Iroquoiens ou les Algonquins qu’ont côtoyés Lahontan et Lafitau. Cette image, à la différence de celles qui vont lui succéder, est très érotisée : les personnages se touchent et s'enlacent. Or, si l'on observe les images des

61. J. F. Lafitau, Moeurs des sauvages américains..., op. cit., III (non paginé dans le texte).

62. Ce film a été réalisé par Gabriel Veyre, opérateur des Frères Lumières; Danse Indienne (Film Lumière $\mathrm{n}^{\circ} 1000,1898$ ).

63. Christophe Colomb, Spanish letter, 12-13, cité par O. P. Dickason, Le Mythe du Sauvage, op. cit., 21-22. 


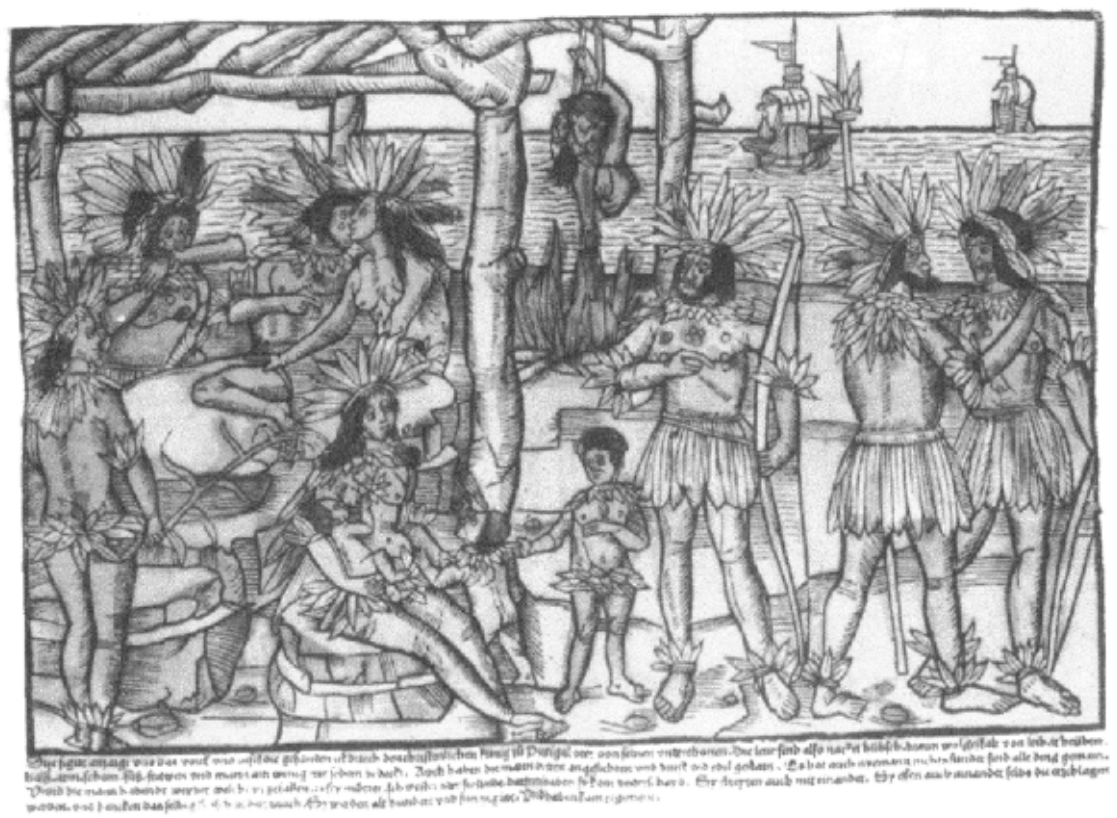

Image 25 : Gravure de Johann Froschauer (Augsbourg ou Nuremberg, vers 1505).

Collection Spencer New York Public Library, Astor, Lenox and Tilden Foundation; tirée de Stephen Greenblatt, Ces merveilleuses possessions (Paris, Belles Lettres, 1996).

récits de voyage du $\mathrm{xvIII}^{\mathrm{e}}$ siècle, cet aspect a totalement disparu, bien que la sexualité demeure un thème récurrent dans les récits.

La perception de la relation que les Amérindiens entretiennent avec la nature s'articule autour de deux discours. Le premier est d'ordre théorique, il idéalise le rapport entre les Amérindiens et la nature; le second - pragmatique - envisage cette relation davantage en termes économiques. Le principal représentant du premier discours au xvIII siècle est le baron de Lahontan. Pour lui, la relation entre les Amérindiens et l'environnement est harmonieuse et propice à l'épanouissement de la raison. Le "noble sauvage», grâce à sa proximité avec la nature, est exempt des péchés et de la corruption de la Vieille Europe. Ces observations ne sont pas de nature ethnographique mais politique: il ne s'agit pas de faire l'apologie des modes de vie amérindiens, mais plutôt d'en faire un argument au service de la critique anticoloniale sous-jacente. L'archétype du «noble sauvage» apparaît également dans le frontispice de l'ouvrage de Lahontan, mais s'exprime cependant de manière différente (images 26 et 27). 

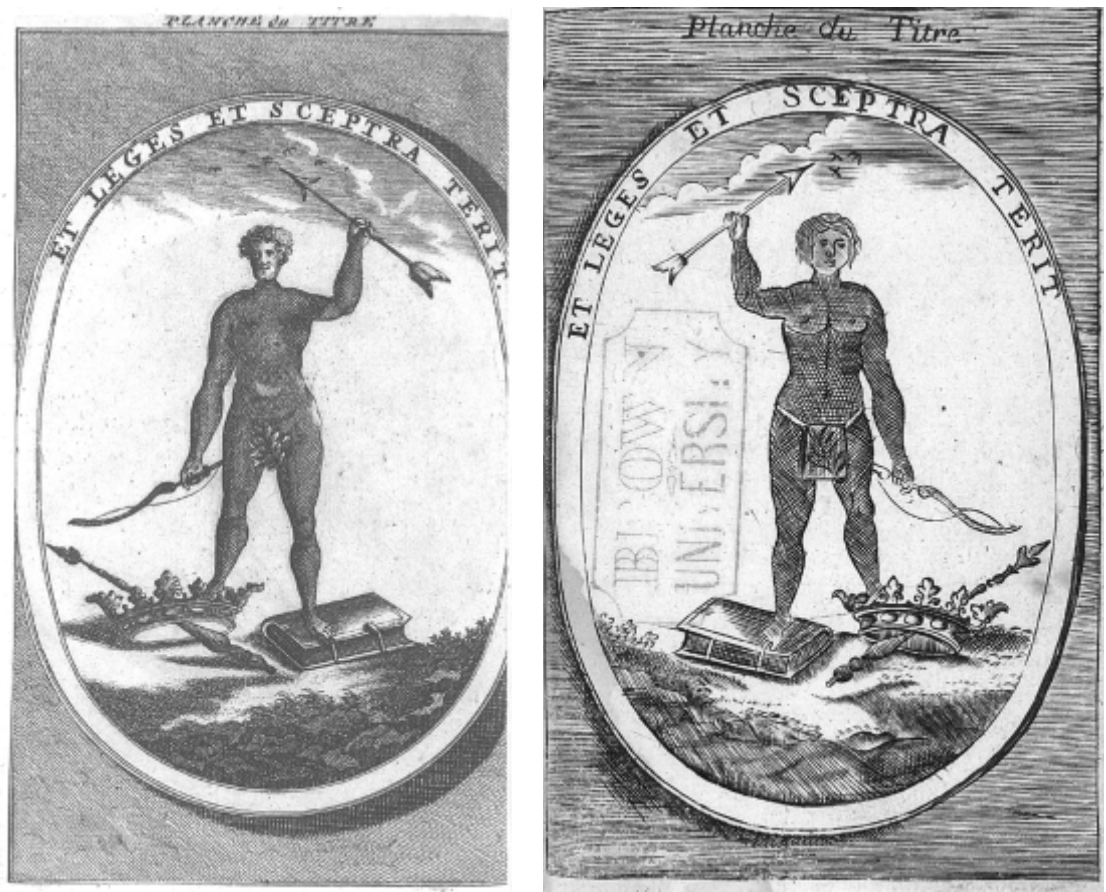

Images 26 et 27: Comme pour les images 21 et 22, ces deux images proviennent de deux exemplaires de la même édition du récit de voyage de Lahontan et chacune a le même emplacement dans le livre; Louis Armand de Lom d'Arce, Baron de Lahontan, op. cit., frontispice. The John Carter Brown Library at Brown University.

Cet homme, aux cheveux courts et ondulés, serait-il un Européen converti à la vie sauvage, et qui, l'arc et la flèche à la main, piétinerait dans un geste d'affront les symboles de l'autorité royale et scripturaire? La compréhension de ces images nécessite quelques explications. Ce personnage est un Amérindien, ce qui est plus vraisemblable si nous regardons l'image 27 tirée de l'édition contrefaite évoquée précédemment. Le graveur, à nouveau, a pris le parti de vêtir l'Indien d'un brayer et de le représenter avec des cheveux longs et raides. L'indianité est signifiée par les symboles de l'arc, de la flèche et de la nudité. La présence du titre en haut de l'image - «il foule au pied et la loi et le sceptre - signale au lecteur que son attention doit se porter sur le geste de rébellion du personnage qui piétine la couronne et les codes de la loi. L'absence de paysage montre que nous sommes dans le registre de l'abstraction et non de l'ethnographie. Cela explique l'entrelacement des symboles de l'indianité et de la royauté. Le corps devient une figure symbolique, il perd toute origine 
ethnique. Le but n'est pas de montrer la spécificité culturelle ou physique de telle ou telle nation: nous ignorons à quel groupe appartient cet Amérindien. Ce que représente le graveur, c’est un stéréotype : celui du "bon Sauvage», stéréotype qui connaît une renaissance au $\mathrm{xvIII}^{\mathrm{e}}$ siècle, mais qui existe dans les écrits depuis le $\mathrm{xvI}^{\mathrm{e}}$ siècle $^{64}$. La représentation de l'arc n'a pas de fonction anthropologique. En effet, le personnage n'est pas en train d'armer son arc pour chasser ou fondre sur l'ennemi; au contraire, il la brandit dans un geste d'affront, et son corps est statique. Nous le voyons ici, la figure du "noble sauvage» ne repose aucunement sur la proximité entre l'homme et la nature - cette dernière est inexistante - mais sur quelques symboles matériels et physiques (l'arc, la flèche et la nudité). Sous le burin du graveur, le geste ethnographique se transforme en arme politique. Nous voyons ici comment le corps amérindien est transformé : il a un faciès européen. Il est également manipulé : il piétine le sceptre et le code de la loi, afin de servir les besoins d'une réflexion idéologique et politique. L'identité du personnage est réduite à des codes figuratifs européens. En utilisant l'archétype du «bon Sauvage», le graveur de Lahontan transmet un message implicite et fait de l'Amérindien le porte-parole de la contestation politique et de la critique de la société coloniale ${ }^{65}$.

L'idéalisation de la relation entre les autochtones et la nature se retrouve chez d'autres auteurs du milieu du siècle, comme chez Bossu ou chez Pierre Pouchot. Bossu - à l'image du graveur de Lahontan -, réutilise le frontispice comme outil polémique (image 18). À la différence de Lahontan, l'image est accompagnée des commentaires de l'auteur qui nous permettent d'interpréter son contenu sous-jacent ${ }^{66}$. Bossu explique que l'image représente le Soleil - chef de la nation des Natchez - assistant en spectateur impuissant à l'assassinat de Cavelier de La Salle par ses compagnons ${ }^{67}$. Le chef indien exprime son mépris et sa révolte en piétinant un coffre rempli de pièces d'or. Derrière lui, le paysage évoque l'Amérique telle qu'elle était avant l'arrivée des Européens, harmonieuse

64. Selon Olive Dickason, les origines du «bon sauvage» remonteraient au philosophe romain Tacite. O. Dickason, op. cit., 13.

65. Sur l'utilisation du "Sauvage» dans le discours politique de Lahontan, voir Lahontan, Euvres complètes, op. cit., 54-68; voir également Rémi Ferland, R. Ouellet, «Les Sauvages de Lahontan: enfants de la nature ou porte-parole des "Lumières" ", dans Gilles Thérien, Les figures de l'Indien, op. cit., 257-269.

66. Jean-Bernard Bossu, Nouveaux voyages aux Indes Occidentales..., op. cit., I: xv-xvi.

67. Le récit de l'expédition de Cavelier de La Salle et de sa mort est raconté par Bossu, ibid., I: 83-107. 
et ignorante de l'avarice. Cette gravure diffère de celle de Lahontan pour plusieurs raisons. Elle fait référence à un événement précis: la mort de l'explorateur du Mississipi. L’Amérindien, qui sert à nouveau de porteparole, est cette fois-ci identifié ethniquement. Le paysage, quant à lui, est représenté par les habituelles collines auxquelles le graveur a ajouté une rivière et quelques personnages. Les points communs avec la gravure de Lahontan sont la signification intrinsèque de l'image et la manipulation du corps. Le paysage en arrière-plan suggère, comme le dit le commentaire, le contraste avec "l'heureuse innocence où vivaient ces peuples avant que les Français arrivassent chez $e^{6} x^{68}$ ». Ici, le paysage n'est pas utilisé dans un but réaliste, mais plutôt idéologique. Une atmosphère de vie se dégage de l'attitude des personnages représentés dans le fond de l'image. Chacun a une activité liée à l'alimentation: une femme allaite son enfant appuyée contre un arbre, deux hommes pêchent, un groupe de personnages déjeune sur l'herbe. Cette ambiance vivante contraste avec la scène de meurtre à laquelle le cacique assiste, impuissant. La gravure est divisée temporellement, le paysage en arrière-plan symbolise le passé, le Soleil au premier plan et l'assassinat de La Salle qui est suggéré, le présent. Cet événement devient le symbole des dérives de la société occidentale. Comme chez Lahontan, le geste de rébellion est exprimé par l'action de piétiner un symbole européen : ici, une caisse remplie d'or. Le corps est à nouveau utilisé dans l'argumentation de l'auteur: la nudité des personnages dans le paysage précolonial symbolise un passé idéalisé et le chef est paré des attributs autochtones masculins qui lui confèrent une autorité (le tatouage du soleil sur sa poitrine ${ }^{69}$, l'arc et la flèche). Sa représentation reprend les archétypes habituels: il porte la coiffe tupinamba, et se tient dans une posture qui rappelle la statuaire antique. Ce personnage constitue une version plus élaborée du «noble Sauvage» que celle de Lahontan. Cela s'explique par le fait qu'il est identifié comme un chef Natchez. Les Natchez étaient très respectés par les Français, probablement parce que, à la différence des autres nations de la Nouvelle-France, ils possédaient un roi, un temple et que leur société était divisée hiérarchiquement $^{70}$. La puissance de ce chef se trouve donc renforcée par le fait

68. Ibid., I : xv.

69. Bossu écrit plus loin que le chef des Natchez, le grand Soleil "portait sur sa poitrine l'image de cet astre [le soleil], dont il prétendait descendre, et qui était adoré sous le nom d'Ouachil, qui signifie le feu très grand ou le feu suprême»; ibid., I: 42.

70. Voir à ce sujet M. Le Page du Pratz, Histoire de la Louisiane contenant la découverte de ce vaste pays, sa description géographique; un voyage dans les terres; l'histoire naturelle; les mours, coutumes et 
qu'il est Natchez, ce qui lui confère une position de juge autoritaire et respectable, apte à dénoncer la corruption des mœurs européennes.

Comme Lahontan et Bossu, Pierre Pouchot idéalise le mode de vie des Indiens: "si l'homme a été créé pour être le maître de la terre, on peut dire qu'il ne paraît l'être véritablement que dans cette partie du monde: n'étant assujetti qu'à ses volontés, sans loi qui le gêne; pouvant satisfaire à tous ses besoins, qui sont peu nombreux, il vit réellement libre ${ }^{71}$.» Cependant, il semble que ce type de commentaire ait une fonction beaucoup moins polémique que chez Lahontan et s'inscrive davantage dans le contexte des idées des Lumières qui sont largement répandues en ce milieu de siècle.

Ce discours théorique reste mineur dans les récits du $\mathrm{XvIII}^{\mathrm{e}}$ siècle: la plupart véhiculent un discours beaucoup plus pragmatique dans lequel la relation des autochtones avec le milieu est liée avant tout à la question de l'exploitation des ressources naturelles. La fréquence de ce discours s'explique, comme nous l'avons vu, par la prééminence de la vision utilitariste de la nature renforcée par la logique coloniale. Nicolas Jérémie en offre un exemple éloquent. Il décrit la région de la Baie d'Hudson et de ses habitants.

C'est « un pays tout à fait inculte et le plus ingrat de tous les pays du monde. Il $\mathrm{y}$ a cependant ces sauvages que nous nommons esquimaux qui habitent dans ces malheureux déserts. Ils sont si farouches et intraitables qu'on n'a pu les attirer à aucun commerce. Ils font la guerre à tous leurs voisins, mangent tout cru leurs ennemis et boivent leur sang. Ils en font même boire à leurs enfants qui sont à la mamelle afin de leur insinuer la barbarie et l'ardeur de la guerre dès leur plus tendre jeunesse. [...] Ils ont de la barbe jusqu'aux yeux qu'ils ne coupent jamais. Ce qui les rend si affreux et si hideux qu'ils ont plutôt la figure de quelque bête farouche que celle d'homme; car ils n'ont que les bras et les jambes qui leur donnent quelque ressemblance avec les autres hommes ${ }^{72}$.

La vision utilitariste se traduit par plusieurs analogies entre le corps et le paysage. La terre et les hommes sont improductifs: les terres sont

religion des Naturels... (Paris, de Bure l’Aîné, 1758), II : 393-394 ; Le Page Du Pratz évoque l'estime que les Français avaient pour les Natchez: «Leurs mœurs étaient d'ailleurs plus douces, leur manière de penser plus vraie et plus remplie de sentiments, leurs coutumes plus raisonnables, $\&$ leurs cérémonies plus naturelles et plus sérieuses; ce qui rendait cette nation plus brillante et qui la distinguait entre toutes les autres, il était même aisé de reconnaitre qu'elle était beaucoup plus policée», ibid., II : 307, 406.

71. P. Pouchot, Mémoires sur la dernière guerre..., op. cit., III : 294.

72. N. Jérémie, «Relation de la Baie d'Hudson par Nicolas Jérémie», loc. cit., V: 307-309. Mes italiques. 
incultes et les hommes refusent de traiter avec les Français. Cette improductivité s'explique par la stérilité des terres et par la sauvagerie des Inuits qui se traduit par un penchant naturel pour la guerre et le cannibalisme. À la différence des Amérindiens qui sont imberbes, les Inuits sont couverts de poils. Nous retrouvons ici la figure de l'homme sauvage hirsute héritée du Moyen Âge qui a dominé les premiers récits européens sur l'Amérique $^{73}$. Il y a donc une correspondance entre l'hostilité de l'environnement, celle de ses habitants, et leur apparence physique quasi animale.

Cette vision pragmatique du corps et du paysage de la Baie d'Hudson pourrait être comparée à celle que Pénicaut, qui a vécu en Louisiane de 1698 à 1721, offre du village des Natchez:

le village des natchez est le plus beau que l'on puisse trouver dans la Louisiane. Il est situé à une lieue au bord du Mississipi. Il est embelli par de très belles promenades, que la nature y a formées sans artifice. Ce sont des prairies à l'entour, garnies de fleurs, entrecoupées de petits coteaux, sur lesquels sont des bosquets de toutes sortes d'arbres odoriférants. Quelques petits ruisseaux d'une eau très claire sortent de dessous une montagne, qui parait à deux lieues de ces prairies, et, après avoir arrosé en quantité d'endroits, ils se ramassent en deux gros ruisseaux, qui font le tour du village, au bout duquel ils se joignent ensemble, en forme d'une petite rivière, qui court sur un gravier fin et va passer par trois villages, qui sont à une demi-lieue l'un de l'autre, et ensuite il tombe à deux lieues de là dans le Mississipi. [...] On trouve dans ce village tout l'agrément possible pour la société avec cette nation qui n'a point les manières farouches des autres sauvages. On y trouve toutes les choses nécessaires à la vie comme bœufs, vaches, biches, cerfs, chevreuils, poules et poulets d'Inde, et quantité d'oies ${ }^{74}[\ldots]$

La première partie de la description est consacrée à l'appréciation esthétique et sensorielle du paysage: de belles promenades, des fleurs, des petits coteaux, des ruisseaux d'eau claire... La vision utilitariste n'apparaît que dans un second temps: «on y trouve toutes les choses nécessaires à la vie». La générosité de la nature s’accompagne du caractère civilisé des autochtones qui «n'ont point les manières farouches des autres nations», ce qui contribue à faire de ce village un lieu idéal pour la colonisation. Cette description semble être le négatif de celle de Nicolas Jérémie. Tous deux

73. Voir O. P. Dickason, Le mythe du sauvage, op. cit.; voir aussi Franck Tinland, L'homme sauvage: Homo ferus et Homo sylvestris de l'animal à l'homme (Paris, L'Harmattan, 2003).

74. André-Joseph Pénicaut, «Relations ou annales véritables de ce qui s'est passé dans le pays de la Louisiane pendant 22 années consécutives", dans Pierre Margry, op. cit., V: 444. Mes italiques. 
véhiculent la même vision utilitariste du corps et de la nature. Pénicaut l'embellit en la projetant dans un avenir idyllique, alors que Nicolas Jérémie la fige dans un présent qui est immuable, car ces terres sont stériles et leurs habitants trop barbares pour en tirer profit. On peut peut-être voir dans ces descriptions les germes de la théorie de la dégénérescence de Buffon: la nature dégénérée expliquerait l'inaptitude des hommes à accéder au progrès ${ }^{75}$.

La vision pragmatique de la relation entre les autochtones et leur milieu s'exprime aussi dans la question de l'agriculture qui permet de mesurer le degré de civilisation des différents groupes. Si une nation amérindienne n'exploite pas les ressources naturelles, elle est perçue comme "sauvage», ne possédant pas les terres sur lesquelles elle vit qui sont alors considérées comme vierges. Le corps amérindien disparaît alors totalement du paysage qui s'offre tout entier à la colonisation. Les groupes pratiquant l'agriculture, comme les Hurons ou les Illinois, sont vus de manière beaucoup plus positive ${ }^{76}$. Ici encore l'argument peut se révéler politique puisqu'il sous-entend l'éventuelle mise à profit de la main-d'œuvre indigène, comme le suggère cet auteur anonyme ayant voyagé en Louisiane : «quelques ennemis du travail que soient les sauvages, je suis convaincu qu'il ne sera pas difficile de les y habituer ${ }^{77}$ ". En construisant un savoir qui catégorise l'altérité en divisant les Amérindiens entre les Sauvages (nomades) et les civilisés (cultivateurs), ce discours transforme la relation horizontale (non hiérarchisée) du rapport à l'environnement dans les sociétés autochtones en la soumettant à des normes européennes ${ }^{78}$.

Une ambiguité apparaît ici. Si le paysage est inexistant dans les gravures, comment les graveurs rendent-ils compte de la relation entre le corps amérindien et le milieu naturel? Comme nous l’avons vu précédemment,

75. Robert E. Bieder, «The Representations of Indian Bodies in Nineteenth-Century American Anthropology ", American Indian Quarterly, 20,2 (Spring 1996) : 165-179.

76. Comme le relève Paolo Carile, Champlain, dans ses descriptions de la Huronie, associe le beau et l'utile: "Ainsi, à l'époque des jardins à la française, le beau pays est celui des Hurons, Amérindiens semi-sédentaires, cultivateurs de maïs et d'autres végétaux comestibles, alors que le pays incommode est identifié au territoire sauvage des Algonquins, chasseurs nomades»; P. Carile, Le regard entravé..., op. cit., 35.

77. Anonyme, Chevalier de, "Relation de la Louisiane ou Mississippi... », dans J.-F. Bernard, dir., Relations de la Louisiane, op. cit., 29; le chevalier de Bonrepos émet la même opinion: "nos ouvriers les tireront bientôt de leur oisiveté et paresse dans laquelle ils vivent n'ayant d'autre exercice que la chasse, la pesche et la guerre "; Chevalier de Bonrepos, Description du Mississipi, op. cit., 6.

78. Sur les rapports entre territoire et altérité, voir F. Walter, Les figures paysagères de la Nation..., op. cit., 21-53. 
un survol de l'ensemble des images laisse paraittre le fait que le paysage se caractérise par l'absence ou l'irréalisme. Le corps occupe, quant à lui, une place beaucoup plus importante. Il est cependant soumis à des variations entre les différents auteurs. Chez Lahontan, les détails anatomiques sont plutôt grossiers et les corps sont statiques. L'indianité est représentée par des symboles: l'arc et la flèche ${ }^{79}$ et la nudité (images 1, 2, 3, 21, 22, 26 et 27). Dans les gravures de Lafitau également, le corps prime sur le paysage (images 4, 5). L'irréalisme du paysage traduit peut-être le désintérêt du graveur. Cette négligence fait écho au texte.

En effet, dans les commentaires de Lafitau sur les gravures au début de l'ouvrage, il n'est jamais question du paysage. Ce qui importe au père jésuite, c'est de montrer telle ou telle coutume et de la comparer avec celle des "peuples des Premiers Temps». Les gravures témoignent ainsi d'un soin très grand à décrire les cérémonies et à représenter le corps. La fête des morts, par exemple, illustre la dernière étape de cette cérémonie qui s'étend sur plusieurs jours (image 28). Le graveur rassemble dans la même image plusieurs actions ayant lieu successivement. Le mouvement des personnages qui marchent en premier plan permet de rendre une impression de progression temporelle et indique au lecteur le déroulement circulaire des événements. Il contribue aussi à rendre cette représentation vivante et vraisemblable. Les précisions ethnographiques concernant les différents traitements du corps des défunts suggèrent l'idée, qui est centrale au rituel, de communion entre les morts et les vivants. La similarité des visages et des postures des personnages suggère que c'est le corps collectif qui est représenté et non le corps individuel. Le regard de Lafitau, que traduit graphiquement le graveur, se concentre donc sur le geste ethnographique. Cette profusion de détails contraste avec l'absence de paysage qui semble n'être là qu'à titre ornemental, comme un décor de théâtre. La question du corps et du paysage chez Lafitau et Lahontan montre l'utilisation distincte que chacun fait de l'image. Chez Lahontan, elle relève du symbolique, alors que chez Lafitau elle est davantage descriptive. Cela rejoint l'hypothèse selon laquelle Lafitau aurait un souci ethnographique plus grand que Lahontan, ce qui ne l'empêche pas de poursuivre, lui aussi, des objectifs politiques ${ }^{80}$.

79. R. Ouellet, «Le discours des gravures...», op. cit., 42.

80. Voir à ce sujet Andreas Motsch, Lafitau et l'émergence du discours ethnographique (Québec/ Paris, Septentrion/Presses de l'Université Paris-Sorbonne, 2001). 


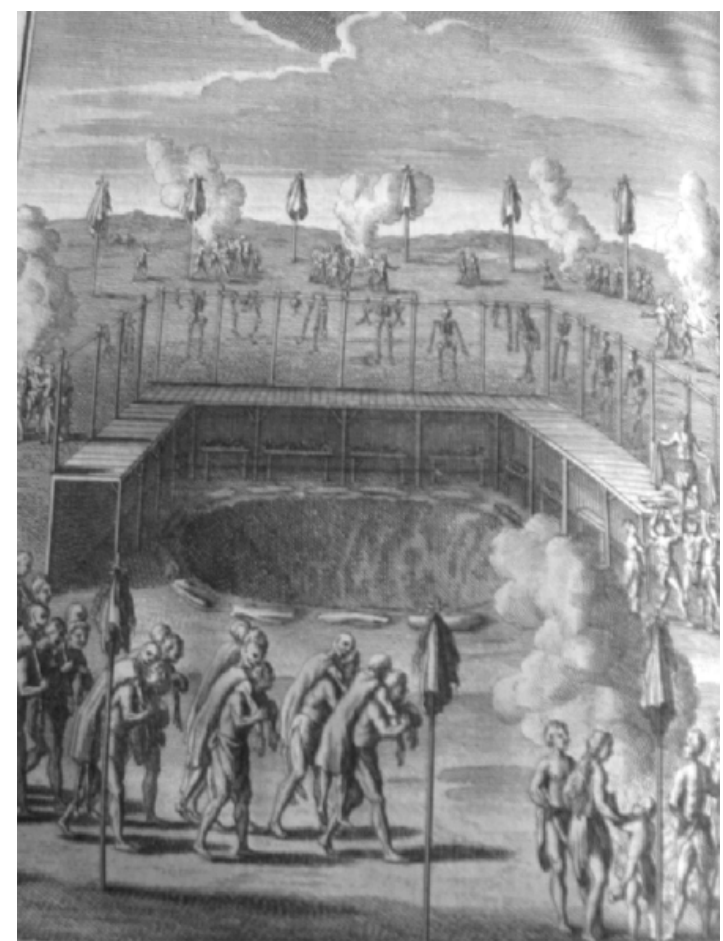

Image 28: Joseph François Lafitau, op. cit., II : 456.

La prééminence du corps par rapport au paysage se retrouve chez Le Page Du Pratz. L'image représentant des Amérindiens Canzès partant à la chasse met l'accent sur le fait que les provisions sont portées par les chiens, mais aussi par les femmes et les filles, ce que les Européens perçoivent comme une preuve de l'exploitation des femmes amérindiennes par les hommes (image 16).

La gravure illustrant la danse pendant la fête du blé chez les Natchez met l'accent, elle aussi, sur les corps et plus particulièrement sur l'organisation de la danse et les mouvements des personnages (image 17). Le musicien assis au milieu bat la mesure et donne le rythme aux danseurs qui l'entourent. Ceux-ci forment deux cercles tournant dans le sens inverse l'un de l'autre: le plus proche du musicien est composé par les femmes, l'autre par les hommes.

Dans une autre représentation iconographique mettant en scène la torture des captifs de guerre chez les Natchez, dont Le Page du Pratz est le premier à donner une description à la fois écrite et picturale, le corps occupe une place prépondérante (image 29). 


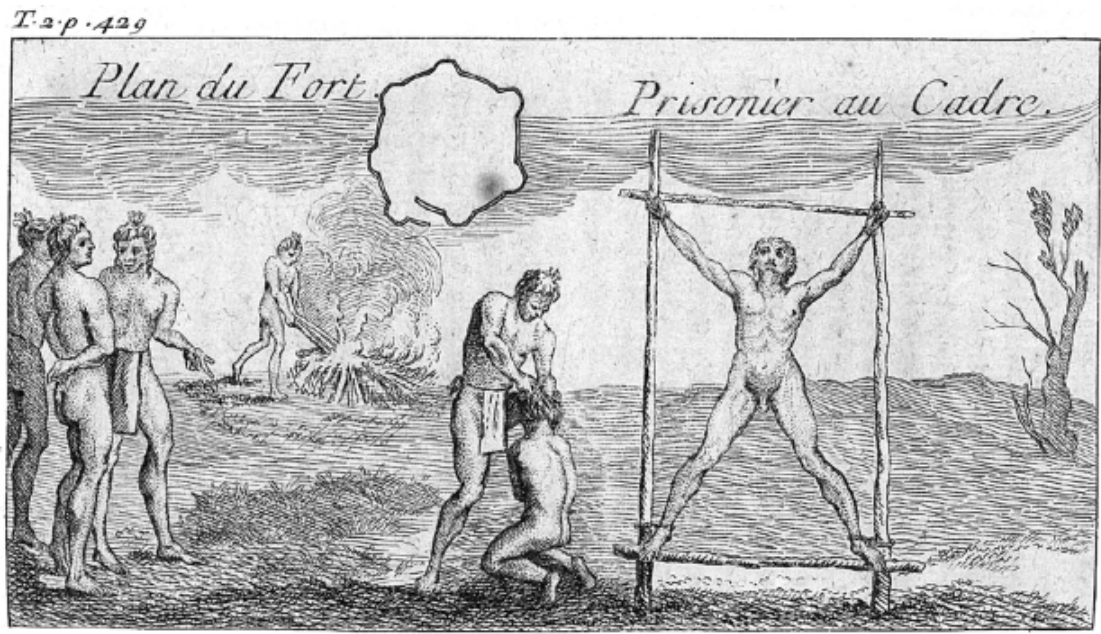

Image 29: M. Le Page Du Pratz, op. cit., II : 429. The John Carter Brown Library at Brown University.

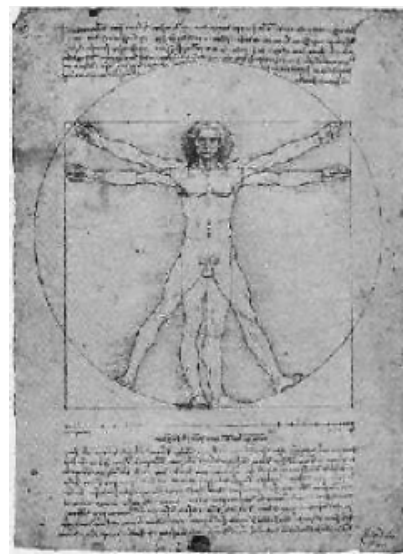

Image 30: Leonardo da Vinci, Schema delle proporzioni del corpo umano.

Source: http :/ / www.lagalerie.fr/repros/VINC6107.htm (consulté le 9 septembre 2005).

Le voyageur explique que lorsqu'un parti de guerre ramène un prisonnier mâle à son village, la joie est générale ${ }^{81}$. On bâtit alors en grande hâte le cadre sur lequel il sera exécuté. Celui qui a capturé le prisonnier le scalpe. Ce dernier est ensuite attaché au cadre. Pendant qu'il entonne sa chanson de mort, encourageant ses bourreaux à davantage de cruauté, tous, les uns après les autres, à commencer par celui qui l'a pris, le brûlent en divers endroits avec des cannes écrasées préalablement enflammées 
sur le feu visible en arrière-plan. L'auteur indique que les souffrances du captif peuvent durer trois jours et trois nuits. À l'extrémité gauche de l'image, un groupe d'hommes, venus pour participer, discutent. Leur attitude nonchalante contraste avec la gravité de la scène qui se déroule devant eux. C'est précisément la participation de tous les membres de la communauté au rituel de torture qui choquait le plus les observateurs européens. La beauté du corps attaché au cadre rappelle Le schéma des proportions du corps humain de Léonard de Vinci ${ }^{82}$ (image 30 ): l'harmonie des différentes parties du corps et la musculature développée du prisonnier évoquent les descriptions émerveillées du corps amérindien par les voyageurs, tandis que les traits de son visage le font plutôt ressembler - une nouvelle fois - à un Européen. Nous constatons donc que cette gravure s'inscrit dans une esthétique du corps héritée de la Renaissance. La beauté de ce corps écartelé surprend face à la brutalité du rituel. Ce mélange d'attirance et de répulsion à l'égard des modes de vie autochtones, que traduit le regard du graveur, est omniprésent dans les récits de voyage en Nouvelle-France. En effet, malgré la répugnance exprimée à l'égard des rituels guerriers, les scènes de torture, de cannibalisme et de prélèvement du scalp sont récurrentes dans les textes et dans les iconographies. Cette ambiguïté reflète les tensions auxquelles le corps est soumis dans les sociétés européennes. Comme l'a écrit Jacques Le Goff, il est à la fois "glorifié et réprimé, exalté et refoulé ${ }^{83}$ ".

Dans l'ensemble des gravures, il appert que l'accent est mis sur le corps et les rituels corporels comme en témoigne la fréquence des thèmes de la danse, des rituels de guerre ou encore de l'habillement. Comparativement à la représentation du paysage qui est souvent homogène, celle des autochtones et des rituels s'avère beaucoup plus nuancée et descriptive. C'est donc le corps et les symboles auxquels il est rattaché qui permettent de situer l'action géographiquement et non le paysage.

Les seules représentations détaillées de la nature dans les récits de voyage semblent être les planches répertoriant la flore et la faune qui figurent dans plusieurs récits de voyage. En voici deux exemples extraits de l'Histoire de la Louisiane de Le Page du Pratz et de L'histoire de la NouvelleFrance de Charlevoix (images 31 et 32):

82. Cette comparaison m’a été suggérée par le professeur Tinguely (Université de Lausanne).

83. Jacques Le Goff, Nicolas Truong, Une histoire du corps au Moyen Âge (Paris, L. Levi, 2003), 30. 


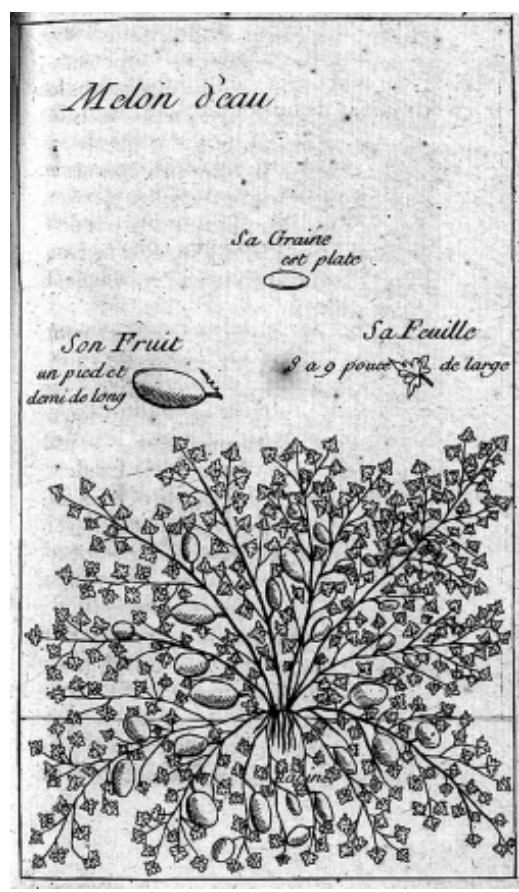

Image 31 : M. Le Page Du Pratz, op. cit., II: 12. The John Carter Brown Library at Brown University.

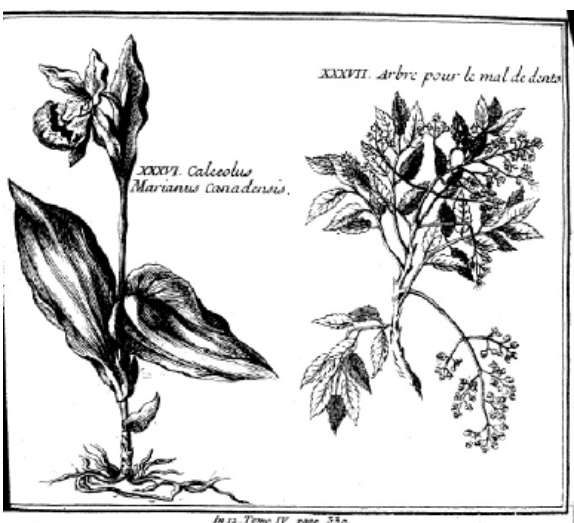

Image 32: Pierre François-Xavier Charlevoix, Histoire et description générale de la NouvelleFrance: avec le journal historique d'un voyage fait par ordre du roi dans l'Amérique Septentrionale, par le R. P. Charlevoix, de la Compagnie de Jésus (Paris, Chez Rolin fils, 1744), IV : 330.

La nature américaine s'y trouve disséquée, déracinée, sortie de son contexte afin d'être classifiée dans le savoir européen. Tout comme le corps, elle est un objet de curiosité. Corps et nature sont l'un comme l'autre représentés sans paysage et de façon abstraite. On retrouve ici la même volonté de nommer que sur la carte de la Rivière Longue évoquée précédemment (image 20). La dénomination permet de gommer l'altérité américaine pour mieux la domestiquer. L’image de «l'arbre pour le mal de dents " (image 32) révèle aussi une tentative de collecte du savoir indigène sur les plantes médicinales, savoir qui est reconnu par les Français. Dans les iconographies, le corps et la nature semblent donc isolés l'un de l'autre, ce qui exprime une volonté de contrôle et peut-être aussi une tentative de déposséder métaphoriquement les autochtones de leur territoire.

À nouveau, ces images pourraient être opposées aux tableaux monumentaux d'Eckhout (images 14 et 15). L'aventure que le portraitiste hollandais a vécue lui a fourni l'occasion d'étudier le corps en partageant le 
quotidien de plusieurs groupes raciaux dont plusieurs vivaient nus, ce qui constituait une expérience artistique unique par rapport aux peintres demeurés en Europe. Le but d'Eckhout était de peindre le corps d'après nature, afin de montrer la diversité ethnique des populations au Brésil. Il ne cherchait ni à enlaidir ni à embellir. Son souci du détail ne se limitait pas aux distinctions ethniques, il représentait aussi les particularités physionomiques de chaque individu ce qu'omet de faire le graveur de Lafitau comme je l'ai dit précédemment. Cette comparaison suggère le fait que la question de l'expérience de l'artiste est aussi déterminante dans la production des images que les normes picturales dans lesquelles l'artiste s'inscrit. Eckhout réalise des œuvres qui sont le résultat d’une expérience de l'Amérique et qu'il veut volontairement fidèles à la réalité, tandis que les illustrateurs de récits de voyage n’ont pas fait le déplacement et s'inscrivent dans une tradition abstraite de représentation du corps et du paysage.

Il semble donc que l'appréciation du paysage ainsi que celle de la relation entre les Indiens et leur milieu sont soumises à des critères qui sont principalement d'ordre économique. L'esthétique et l'utilitaire se confondent dans la représentation littéraire du milieu américain afin d'affirmer une prise de possession effective ou projective du territoire.

\section{4 - L'APPROPRIATION PHYSIQUE DU TERRITOIRE}

L'appropriation du paysage par les voyageurs n'est pas seulement discursive. Elle est aussi «physique ${ }^{84}$ ». Comme l'a expliqué Claude Reichler, le paysage n'est pas uniquement un regard porté sur les choses, les cinq sens sont convoqués dans cette expérience corporelle entre l'homme et le monde ${ }^{85}$. Le rapport physique des voyageurs avec l'espace américain est

84. Le paysage ne se limite pas à la vue que l'on a d'un espace, c'est une expérience physique dans laquelle tous les sens sont engagés. Plusieurs travaux ont montré l'importance des autres sens que la vue dans l'appréciation du paysage: l'odorat, le toucher. Voir notamment, Olivier Balay, Discours et savoir-faire sur l'aménagement de l'environnement sonore urbain au XIX ${ }^{\mathrm{e}}$ siècle, thèse de doctorat (urbanisme et aménagement), Université de Grenoble II, 1992; les recherches menées sur le climat comme élément du paysage ont aussi mis en évidence l’importance du corps; voir Martin de la Soudière, L'hiver, à la recherche d'une morte saison (Lyon, La manufacture, 1987); voir Alain Corbin, "Pour une histoire de la sensibilité au temps qu'il fait», conférence dans le cadre du Séminaire Le paysage: perceptions, représentations, théories. Appropriations du paysage et identités culturelles (XVIII - -XIX ${ }^{\mathrm{e}}$ siècles), le 20/04/04 (Université de Lausanne); voir aussi C. Reichler, dir., Le bon air des Alpes/The Good Alpine Air (Grenoble, Institut de géographie alpine; A. Colin, 2005).

85. Claude Reichler, "Le paysage au-delà des machines qui le donnent à voir», Colloque «Paysage en poésie»- Rencontres internationales du paysage, 5-8 juillet 2004, Château d'Aigle, Suisse. 
inhérent au concept de récit de voyage, ce dernier se définissant comme la narration écrite d'un déplacement effectué par un voyageur ${ }^{86}$. La perception de l'environnement n'est pas seulement culturelle, sociale ou politique, elle est aussi personnelle. Elle dépend de la capacité d'adaptation du voyageur.

Dans la partie septentrionale de l'Amérique, le principal obstacle à cette adaptation est le climat. C'est pourquoi ce thème monopolise le champ de la représentation du paysage chez plusieurs voyageurs. Pour Charlevoix, le paysage disparaît littéralement sous la neige, il est gommé par le manteau neigeux: "Comme la terre est partout couverte de cinq ou six pieds de neige, ces courses ne m'ont pas mis beaucoup en état de vous parler de la nature du pays ${ }^{87}$.» Pour le père jésuite donc, le paysage hivernal n'existe apparemment pas, car les terres sont inexploitables pendant cette saison. Là encore, la conception utilitariste de la nature semble dominer. La question du froid occupe une grande place dans les récits et, malgré un siècle d'expérience hivernale, il continue à surprendre les nouveaux arrivants tout au long de la période. En effet, les premières remarques du père Charlevoix et du baron de Lahontan à propos du Canada concernent le froid. Bougainville, dans les années 1750, est lui aussi frappé par la rigueur hivernale: «le Canada est un pays extrêmement froid, où les neiges sont abondantes, où l'hiver dure ordinairement six mois ${ }^{88}$ ". Ce discours dramatique renvoie à l'anxiété physique, à cette peur de la mort qui s'empare des premiers arrivants. Ce discours est alimenté par des anecdotes qui circulent dans la colonie et dans la métropole par le biais - entre autres - des récits de voyage. Ces anecdotes appartiennent à une mythologie, comme cette remarque de Charlevoix: «aussi n’ai-je jamais passé d'hiver dans ce pays, que je n'aie vu apporter à l'hôpital quelqu'un à qui il fallait couper des bras et des jambes gelées ${ }^{89}$ ". Ces rumeurs rappellent celles que l'anthropologue Martin de La Soudière ${ }^{90}$ a relevées lors de son enquête à Belbeyre ${ }^{91}$. Les habitants de cette commune française

86. Voir la définition proposée par Claude Reichler dans le cadre du projet Viatica; http:// www.viatica.info/

87. P. F.-X., Charlevoix, Histoire et description générale..., op. cit., III : 85.

88. Lahontan se plaint du froid dès la première lettre: à peine débarqué à Québec, «Je ne puis vous rien dire encore de ce pays, si ce n'est qu'il y fait déjà un froid à mourir». Voir Louis-Antoine de Bougainville, Écrits sur le Canada. Mémoires, journal, lettres, (Québec, Pelican/Klincksiek, 1993), 72; Lahontan, Nouveaux Voyages, op. cit., 262.

89. P. F.-X., Charlevoix, Histoire et description générale..., op. cit., III : 165.

90. M. de la Soudière, L'hiver, à la recherche d'une morte saison, op. cit.

91. Belpeyre est située sur un plateau à l'intersection de la Haute-Loire, du Cantal et de la Lozère. 
réputée pour la sévérité de son climat se sont approprié l'hiver et en ont fait un élément majeur de leur identité, notamment par la transmission de légendes destinées à effrayer les étrangers. La dramatisation de l'hiver permettrait d'affirmer une singularité et de rejeter l'autre.

Parallèlement au discours pessimiste, les relations de voyage au Canada livrent une perception idéaliste qui exprime un autre type d'emprise identitaire. Ce discours qui véhicule une image plus positive en minimisant la dureté du froid témoigne, comme l’a suggéré Sophie Lamontagne, de «la volonté de vaincre ${ }^{92}$ ». Il montre aussi un désir de convaincre le destinataire de l'intérêt de la Nouvelle-France. Pour Dièreville, qui voyage en Acadie au début du xviII ${ }^{\mathrm{e}}$ siècle, le froid, considéré par d'autres comme le principal frein à la colonisation, n'est plus un obstacle.

De ce séjour les habitants

Où chacun pour vivre travaille

Ne laissent pas d'être contents;

On ne leur parle point d'impôt ni de taille

Ils ne payent quoi que ce soit;

Chacun sous une rustique toit

Vide en repos sa huche et sa futaille

Et se chauffe bien en temps froid,

Sans acheter le bois denier ni maille:

Où trouve-t-on des biens si doux ${ }^{93}$ ?

Dièreville, qui écrit à l'intendant Michel Bégon, cherche à désamorcer le discours dramatisant sur le froid en évoquant la profusion du bois de chauffage, afin de signifier que le Canada peut être conservé à faible coût. Le poème sous-entend une autre idée: celle de l'adéquation du corps créole et de l'environnement américain ${ }^{94}$. Les habitants sont "contents", car ils savent se prémunir de l'hiver et égalent ainsi les Amérindiens dans leur aptitude à résister au froid. On trouve ce discours chez les jésuites notamment dans ce témoignage du père Marest:

92. S.-L. Lamontagne, L'hiver dans la culture québécoise..., op. cit., 39-46.

93. Sieur de Dièreville, Relation du voyage du Port Royal de l'Acadie ou de la Nouvelle-France... par M. Dièreville,... Ensuite de la relation, on a ajouté le détail d'un combat mené entre les Français et Acadiens contre les Anglais (Rouen, J.-B. Besongne, 1708), 78.

94. L’appropriation de l'hiver est un élément important de l’identité québécoise. Pour le poète Gilles Vigneault, l'hiver serait l'essence même du Québec: «Mon pays, ce n'est pas un pays c'est l'hiver. Mon chemin ce n'est pas un chemin, c'est la neige », Gilles Vigneault (paroles et musique), "Mon pays"; cette chanson figure sur l'album Chemin faisant, cent et une chansons, (Le Nordet GVNC-1017) disque 3. 
Ce long hiver quoiqu'il soit toujours froid ne l'est pas toujours également. Il y a souvent à la vérité des froids excessifs pendant lesquels on ne se montre pas impunément dehors. Il y en a peu d'entre nous qui n'en aient porté les marques; et un matelot entre autres y a perdu les deux oreilles: mais aussi il y a de beaux jours. Ce qui m'y plait davantage c'est qu'on n'y voit point de pluie; et qu'après certain temps de neige et de poudrerie, l'air y est net et clair $^{95}$.

Le père Nau, quant à lui, estime que «l'hiver n'y est pas si rude qu'on le dit en France; jamais on ne voit plus de trois ou quatre jours de suite d'un froid bien piquant. J'ai eu tous les ans plus de froid en France que je n'en ai eu au Canada ${ }^{96}$.» Comme dans le cas de l'idéalisation du paysage observée précédemment, ce discours opère une appropriation de l'hiver mais cette fois-ci par le biais du corps, ce dernier servant d'argument pour légitimer l'implantation française. Le corps est le lien entre le paysage et l'homme. Ce discours évoque celui des colons américains qui, comme l'a expliqué l'historienne Joyce Chaplin, ont cherché à prouver l'inadaptation du corps amérindien au milieu américain afin de justifier leur prédestination à occuper les lieux ${ }^{97}$. La coexistence de ces deux visions contradictoires de l'hiver, l'une tragique, l'autre idéaliste, illustre donc, d'une certaine manière, les hésitations de la colonisation française partagée entre la volonté de conserver les colonies continentales et la tentation de les abandonner.

L'adaptation du corps au milieu se fait aussi par l'imitation de plusieurs techniques autochtones. C'est ce que montre, par exemple, l'image de Bacqueville de la Potherie représentant un soldat canadien en hiver (image 33).

Le capitaine Pouchot, qui souhaite améliorer l'efficacité de l'armée française au Canada, estime que l'habillement des Indiens «serait fort bon pour des troupes qu'on voudrait faire marcher l'hiver, et éviterait bien des maux aux soldats ${ }^{98}$ ». Si Pouchot vante les qualités des vêtements autochtones, pour le baron de Lahontan, ce sont les raquettes qui sont très utiles:

95. Reuben Gold Thwaites, dir., The Jesuit Relations and Allied Documents : Travels and Explorations of the Jesuit Missionaries in New France, 1610-1791 (Cleveland, Ohio, Burrows Brothers Company, 1896-1901), lxvi, 113.

96. Ibid., lxviii, 260.

97. «Observing that Indians suffered from disease and epidemics declined in numbers while the English survived epidemics and grew in population, settlers congratulated themselves because they seemed to have been the foreordained inhabitants of America. »; J. E. Chaplin, "Natural Philosophy and an Early Racial Idiom in North America... », loc. cit., 252.

98. P. Pouchot, Mémoires sur la dernière guerre..., op. cit., III : 286-288. 


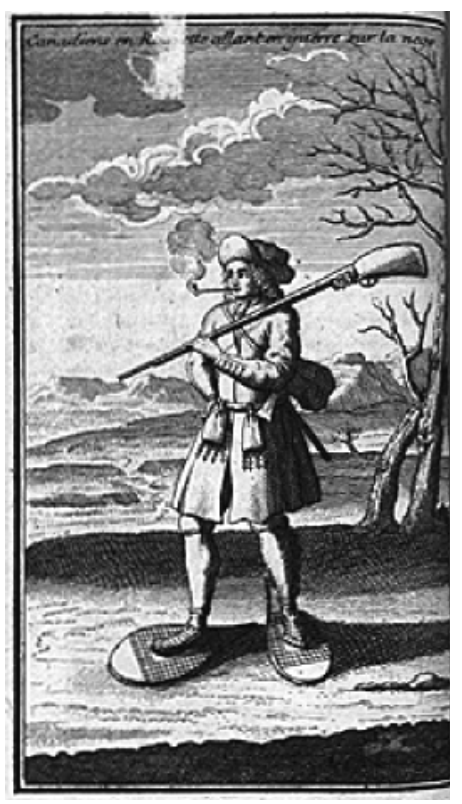

Image 33: M. de Bacqueville de la Potherie, Histoire de l'Amérique septentrionale, contenant le voyage du fort Nelson dans la baie d'Hudson, à l'extrémité de l'Amérique... (Paris, Nion et Didot, 1722), I: 61. The John Carter Brown Library at Brown University.

elles «sont si nécessaires qu'il serait impossible non seulement de chasser et d'aller dans les bois mais même d'aller aux églises pour peu qu'elles soient éloignées des habitations ${ }^{99}{ }^{\text {}}$. L'adaptation du corps au milieu américain passe donc par le métissage: pour y survivre et en tirer profit les Européens doivent se comporter «à l'Indienne».

\section{CONCLUSION}

Le paysage de la Nouvelle-France dans les récits de voyage est souvent perçu par les auteurs de relations de voyage d'un point de vue utilitariste. La nature intéresse avant tout en tant que richesse potentielle à exploiter. Le récit de voyage sert alors à inventorier les ressources. Cet article a tenté de montrer également que le paysage a une fonction politique : il sert de projection aux désirs du colonisateur et devient un instrument de propagande. Ces descriptions de la nature américaine se traduisent peu cependant dans les gravures, sauf à la fin de la période. Cela s'explique par deux raisons. La première est que le texte est le produit de l'expérience du

99. Lahontan, Euvres complètes, op. cit., 326; Lafitau reconnaît lui aussi la nécessité d'utiliser des raquettes: "dans les neiges où il n'y a point de chemin frayé, ils sont obligés de se servir de raquettes, sans quoi toute sorte de voyages, ou pour guerre ou pour chasse, \&c. leur seraient absolument impossibles. »; J. F. Lafitau, Mœurs des sauvages américains..., op. cit., III : 200. 
voyageur, expérience qui est personnelle et physique comme nous l'avons vu. La seconde découle de la première: le texte est aussi le fruit d'un voyage et d'une entreprise qui s'inscrivent dans le contexte de la colonisation - qu'ils la défendent ou la critiquent. Les images iconographiques, quant à elles, sont beaucoup plus schématiques et recourent davantage au registre du symbolique. Le paysage importe peu aux graveurs. Nul besoin de représenter la nature américaine pour faire comprendre au lecteur du $\mathrm{xvIII}^{\mathrm{e}}$ siècle où se déroule la scène: le corps amérindien, et quelques symboles qui y sont rattachés, suffisent à le transporter dans l'univers américain.

La représentation du corps amérindien dans sa relation au milieu témoigne, une nouvelle fois, de cette vision utilitariste. Le corps est lui aussi manipulé au gré des desseins de l'auteur. Corps et paysage servent donc tous deux de projection au discours politique. Les représentations ne sont donc pas des choses inertes, elles agissent sur la réalité sociale et politique: elles sont issues du processus de colonisation tout en y participant à un niveau épistémologique.

L'analyse montre finalement qu'une place plus faible est accordée au paysage dans les textes comme dans les images et que le corps occupe l'essentiel de l'espace de la représentation. Il ne faudrait pas y voir cependant une volonté consciente de la part des voyageurs et des graveurs de mettre en avant le corps au détriment d'une représentation du paysage. On peut cependant en déduire une curiosité à décrire les corps et les rituels corporels, intérêt qui rencontre celui du public. L'absence de paysage s'explique avant tout par le fait que ce dernier intéresse encore assez peu la littérature et l'art pictural en général. L’intérêt pour le corps s'inscrit également dans des traditions iconographique et littéraire, qui ont contribué à forger des stéréotypes (l'homme sauvage, le cannibale) que les gravures du $\mathrm{XvIII}^{\mathrm{e}}$ participent à enraciner. Le corps est au centre de l'image, il est donc, d'une certaine manière, le noyau emblématique de la représentation de l'Amérique. 